\title{
Yeşil Tedarik Zinciri Yönetiminde Çok Kriterli Karar Verme: Otomotiv Ana Sanayi Örneği ${ }^{1}$
}

\author{
Gözde Koca ${ }^{2}$ \\ Sema Behdioğlu ${ }^{3}$
}

\begin{abstract}
Yeşil Tedarik Zinciri Yönetiminde Çok Kriterli Karar Verme: Otomotiv Ana Sanayi Örneği

Öz

Çalışmada Sürdürülebilir Tedarik Zinciri Yönetimi'nin (STZY) çevresel boyutu olan Yeşil Tedarik Zinciri Yönetimi (YTZY), Türk Otomotiv Ana Sanayi bağlamında, Çok Kriterli Karar Verme (ÇKKV) metotları kullanılarak incelenmiştir. Çalışmanın ilk aşamasında, YTZY ait kriterler belirlenmiştir. İkinci aşamada, kriterler oran ağılıkları tekniği ile ağırlıklandırılmıştır. Ağırlıklandırma sonucunda, yeşil geri dönüşüm ve yeşil tasarıma ait alt kriterlerin ön plana çıktığı belirlenmiştir. Üçüncü aşamada, Ford OTOSAN'ın fabrikaları mutlak sayıları, bulanık sayıları ve sezgisel bulanık sayıları içeren 8 ayrı metot kullanılarak, YTZY kriterlerine göre değerlendirilmiştir. Dördüncü aşamada ise karar verici olarak yer alan 11 firmanın önem ağırlıkları değiştirilerek 10 farklı senaryo oluşturulmuştur. Böylelikle Ford OTOSAN'ın fabrikalarının sıralamalarındaki değişimler duyarlıık analizleri ile izlenmiştir. Sonuçta, bu çalışma için Entropi ile Ağırlıklandırılmış Sezgisel Bulanık TOPSıS Metotları daha etkin olarak görülmüştür.
\end{abstract}

Anahtar Kelimeler: Yeşil Tedarik Zinciri Yönetimi, Çok Kriterli Karar Verme, Entropi, Sezgisel Bulanık TOPSIS

\begin{abstract}
Multi-Criteria Decision Making in Green Supply Chain Management: An Example of Automotive Main Industry Abstract

In this study, the Green Supply Chain, which is the environmental dimension of the Sustainable Supply Chain Management was examined within the framework of the Turkish Automotive Main Industry by using Multi Criteria Decision Making methods. In the first phase, the criteria were determined. In the second phase, criteria weighted. The sub-criteria of the green recycling and the green design were determined to be the foreground. In the third phase, the factories of Ford OTOSAN were evaluated by using 8 different methods which include absolute numbers, fuzzy numbers and intuitive fuzzy numbers. In the fourth phase, 10 different scenarios were developed. In this way, the changes in the grading of the factories of Ford OTOSAN were traced with sensitivity analysis. In conclusion, Intuitionistic Fuzzy TOPSIS methods using entropy weight were seen as more effective ones.
\end{abstract}

Keywords: Green Supply Chain Management, Multi Criteria Decision Making, Entropy, Intuitionistic Fuzzy TOPSIS

\section{Giriş}

Günümüzde çevreye olan ilgi giderek önem kazanmaktadır. Özellikle Sanayi Devrimi'nden sonra dünya her geçen gün daha da kirlenmektedir. İnsanlar yalnızca günümüz kaynaklarını kirletmekle kalmamakta, aynı zamanda gelecek nesillerin hayati kaynaklarına erişimini de etkilemektedir. Geçmişte çevreyi korumaya yönelik talep ve farkındalık bir ana akım hareketi değilse de günümüzde önemli bir faaliyet haline gelmiştir. Özellikle de üretim süreçleri çevre üzerinde en çok zarar veren uygulamalar olarak görülmektedir. Geleneksel tedarik zinciri yönetimi, çevre üzerindeki olumsuz etkileri nedeniyle mevcut paydaş ihtiyaçlarına uygun bir yanıt verememekte ve sürdürebilirliği sağlayamamaktadır.

\footnotetext{
${ }^{1}$ Bu çalışma Dumlupınar Üniversitesi Sosyal Bilimler Enstitüsü Ekonometri Anabilim Dalı’nda Prof. Dr. Sema Behdioğlu danışmanlığında Gözde Koca tarafından hazırlanan "Bütünleşik Bulanık Çok Kriterli Karar Verme Metotları: Türk Otomotiv Ana Sanayi Örneği" adlı doktora tezinden türetilmiştir.

2 Dr. Öğr. Üyesi, Bilecik Şeyh Edebali Üniversitesi, iỉBF, İşletme Bölümü, gozde.koca@bilecik.edu.tr, Yazar ORCID bilgisi: https://orcid.org/0000-0001-6847-6812

3 Prof. Dr., Dumlupınar Üniversitesi, IiBF, Ekonometri Bölümü, sema.behdioglu@dpu.edu.tr, Yazar ORCID bilgisi: https://orcid.org/0000-0002-4759-2088
} 
Sürdürülebilir Tedarik Zinciri Yönetimi (STZY), sürdürülebilir kalkınmanın ekonomik, sosyal ve çevresel boyutları çerçevesinde tedarik zinciri boyunca malzeme ve bilgi akışının yönetimini sağlamaktadır. STZY'nin araştırma alanında artan bir ilgi olduğunu gösteren birçok çalışma yapılmıştır. Özellikle de STYZ'nin çevresel boyutu olan Yeşil Tedarik Zincirine (YTZY) odaklanacak ve otomotiv gibi büyük bir endüstrinin etkisini değerlendirecek çalışmalara ihtiyaç duyulmaktadır. YTZY, çevresel intiyaçlara ve kurallara bağlı kalarak sürecin ve ürünlerin performansını arttıran bir yaklaşımdır.

Şirketler YTZY'yi stratejik bir analiz aracı olarak görmeye başlamışlardır. Bu artan ilgi, tüm üreticilerin hava, su ve toprak kirliliği içeren çevre için hassas olması gerektiğini kanıtlamaktadır. Bunlar, günümüzde birçok uluslararası anlaşmaya ve üstesinden gelinmesi gereken iş birliğine ihtiyaç duyan en zorlu konulardan biri haline gelen küresel ısınmaya neden olmaktadır. Aynı zamanda hem karlılık hem de çevresel duyarlıık faktörleri dikkate alınmaktadır. Bu duyarlılık faktörlerini en fazla dikkate alan endüstrilerden olan otomotiv endüstrisi, dünyanın birçok ülkesinde büyük ve büyüyen bir endüstridir. Özellikle ucuz işgücü piyasasına sahip, gelişmekte olan ülkelerde otomobil endüstrisine karşı büyük ilgi vardır. Türkiye'de bu ülkeler arasında bulunmaktadır. Otomotiv endüstrisi, Türkiye'de istihdama önemli katkılar sağlayan en büyük ve en yenilikçi sektörlerden biridir. Bu durum, Türk otomobil endüstrisinin neden ülke ekonomisi için çok önemli olduğunu anlatmaktadır. Otomotiv endüstrisinde, çevre dostu uygulamaların başında, daha az yakıt tüketimi veya kurşunsuz benzin kullanılması ve çevre üzerinde daha az olumsuz etki yaratması gibi girişimler gelmektedir. Bu gibi girişimlerde YTZY'yi kaçınılmaz kılmaktadır. Dolayısıyla bu araştırmanın amacını da gelişmekte olan ülkelerde ekonomi ve istihdam faktörlerine büyük etkisi olan otomotiv endüstrisinde YTZY uygulamalarını Türk Otomotiv Ana Sanayi bağlamında Çok Kriterli Karar Verme (ÇKKV) metotlarını ele alarak incelemek oluşturmaktadır. Bu açıdan bu çalışmanın ilerleyen bölümlerinde ilgili literatürde yapılmış çalışmalar hakkında bilgi verilmiş ve kullanılacak olan mutlak sayıları, bulanık sayıları ve sezgisel bulanık sayıları içeren 8 ayrı ÇKKV metotlarından bahsedilmiştir. Daha sonraki bölümlerde analizler detaylı bir şekilde anlatılmıştır. Son bölümde ise sonuç ve değerlendirme sunulmuştur.

\section{Literatür Taraması}

Son yıllarda, çevre ve iklim değişikliklerinden dolayı endişeler giderek arttığından YTZY araştırmaları daha fazla ilgi çekmeye başlamıştır. YTZY, organizasyonların ekolojik etkinliğini arttırırken, çevresel risklerini ve etkilerini azaltarak bir organizasyonun kar ve pazar payı hedeflerine ulaşmak için önemli bir felsefe olarak meydana gelmiştir. Tüketici baskılarının artması, mevzuatların katılaşması ve kaynakların kısıtlılı̆ı gibi farklı nedenlerle üreticilerin, çevresel etkileri minimuma indirmek, rekabet üstünlüğünü elde etmek ve sürdürmek için çevre ile ilgili projelerini stratejik planlama programlarına etkin bir şekilde bütünleştirmeleri zorunlu kılınmıştır. Ayrıca, YTZY'e adapte olunmasının, organizasyonların yeşil girişimlere olan eğilimlerini arttırdığı ve baskıların etkilerini azalttığı görülmüştür. Özellikle gelişmekte olan ülkelerde, benimsenen yeşil girişimlerin çoğu, kirliliği ya da atığı azaltmak için proaktif bir yaklaşım izlemek yerine, "boru sonu" çözümleri (kuruluşun yarattığı olumsuz çevresel etkileri ortadan kaldırmaya ya da azaltmaya çalışan geleneksel komuta ve kontrol) olarak kalmaya devam etmektedir. Geleneksel "boru sonu" yaklaşımı yalnızca doğayı kirleten maddeleri bir formdan diğerine dönüştürmektedir. Bu söz konusu maddeleri ortadan kaldırmamaktadır. YTZY kavramı ise "boru sonu" yaklaşımının aksine, hammaddelerin satın alınımından, nihai 
kullanıma ve bertaraf edilmesine kadar organizasyonun ürün ve hizmetlerine yönelik tüm çevresel sorumluluğunu üstlenmektedir.

Literatürdeki YTZY'e kapsamında araştırmaları iki grupta inceleyebiliriz. İlk grupta otomotiv sektörünü YTZY açısından inceleyen araştırmalar yer almaktadır. Bu araştırmaları inceleyecek olursak, Diabat vd. (2013), çalışmalarında, bir otomobil fabrikasındaki yeşil tedarik zinciri uygulamaları ile performans sonuçları arasındaki ilişkiyi incelemişlerdir. Sonuçta çevre tasarımı, müşterilerle işbirliği ve ters lojistik en çok önem verilen üç ana faktör olarak belirlenmiştir. Drohomeretski vd. (2014), Brezilya otomotiv sektöründe YTZY uygulamalarındaki motive edici faktörleri ve zorlukları belirlemişlerdir. Bunun için üç vaka incelemesi ve 13 röportaj yapılmıştır. Sonuçta bu çalışmada YTZY uygulamalarının benimsenmesi için otomotiv sektöründeki şirketlerin bilinçlendirilmesi ve yönlendirmesi gerektiğini ifade etmişlerdir. Luthra vd. (2011), Hint otomobil endüstrisinde YTZY'yi gerçekleştirirken karşılaşılan engelleri tanımlamayı amaçlamışlardır. Sonrasında bu engeller arasındaki ilişkiyi incelemiş ve sınıflandırmışlardır. Vanalle ve Santos (2014), Brezilya otomotiv sektöründe tedarik zincirleri üyelerine tedarikçi seçme ve geliştirme sürecinde düşünülen çevresel, finansal ve operasyonel performansla ilgili faktörlerin yanı sıra sürdürülebilirliğin en değerli uygulamalarını tanımlamışlardır. 20 şirketle görüşmüşlerdir. Şirketler tarafından en çok değer verilen sürdürülebilirlik uygulamaların başında, tehlikeli maddelerin kullanımını ortadan kaldırmak veya azaltmak konusunun geldiğini ortaya koymuşlardır. Operasyonel performans, zamanında teslim edilen ürünlerin miktarı, kalite yönetimine bağlılık, teslimat süresi ve sipariş uyumluluk oranı ise diğer sürdürülebilirlik konuları arasında yer almıştır. Sanghavi vd. (2015), çalışmalarında son derece rekabetçi olan otomotiv endüstrisinde YTZY uygulamalarını sunmuşlardır. Ağırlıklı olarak, otomotiv şirketlerinin yeşil tasarım, yeşil girişim uygulamaları ve karşılaştıkları engeller üzerinde durmuşlardır. Tedarik zincirlerinin yeşermesi, pazarlama performansı ile çevre sorunları dengelendiğinde gerçekleşeceğini ifade etmişlerdir. Demirci (2014) ise Türk Otomotiv Sanayi'nde bulunan 5 ana sanayi üzerinde ampirik bir çalışma gerçekleştirmiştir. Sorulan sorular neticesinde YTZY'nin tam olarak uygulanamadığını ve Türk üreticiler için yeşil tasarım ve yeşil satın alma kavramlarının oldukça yeni kavramlar olduğunu ifade etmiştir. Jain ve Sharma (2012), çalışmalarında YTZY uygulamaları literatürünü gözden geçirmişler ve Hindistan'da literatürde yer alan bu uygulamaların ne kadarının gerçekleştiğini incelemişlerdir. Verileri, 10 firmanın anketinden derlemişlerdir. Anket sonuçlarına göre, bazı YTZY uygulamalarının daha başlangıç aşamasında olduğu görülmüştür.

Ikinci grupta ise, YTZY'yi ÇKKV yöntemleri ile inceleyen çalışmalar yer almaktadır. Sarkis (2003), YTZY'nin bileşenleri ve unsurları üzerine odaklanan Analitik Ă̆ Sürecini (ANP) kullanarak stratejik bir karar çerçevesi sunmuştur. Chen vd. (2012), YTZY'nin karmaşık strateji seçimi problemlerini çözmek ve iş fonksiyonlarının en önemli faaliyetlerini değerlendirmek için ANP'yi kullanmıştır. Diabat ve Govindan (2011), Yorumlayıcı Yapısal Modelleme (ISM) çerçevesi kullanarak YTZY'nin uygulanmasını etkileyen bir itici model geliştirmişlerdir. Shang vd. (2010), bir faktör analizi temelinde, kritik YTZY yeterlilik boyutlarını ve firma performansını araştırmış ve yeşil imalat ve ambalajlama, yeşil pazarlama, çevreci katılım, yeşil tedarikçiler, yeşil stok ve yeşil eko tasarım olmak üzere altı boyut tespit etmişlerdir. Öte yandan, Mathiyazhagan vd. (2013), YTZY konseptinin uygulanmasına ilişkin engelleri analiz etmiş ve yirmi altı engel belirlemiştir. YTZY'nin en önemli konularından biri, yeşil tedarikçilerin değerlendirme ve seçim sürecidir. Shen vd.(2013), YTZY'yi inceleyerek yeşil tedarikçilerin değerlendirmesi için bulanık bir TOPSIS yaklaşımı önermiştir. Büyüközkan ve Cifci (2012), 
entegre bir metodoloji geliştirmiş ve gerçek bir vaka çalışmasında bulanık ortamda yeşil tedarikçi değerlendirmesi için DEMATEL, ANP ve TOPSIS yöntemlerini kullanarak uygulamışlardır. Tseng ve Chiu (2013), bir firma için uygun çevresel ve çevresel olmayan YTZY ölçütlerini belirleyerek ve değerlendirerek, alternatif tedarikçileri sıralamak için gri ilişkisel analizi kullanmışlardır. Lin (2013), proaktif firmaların ekonomik ve çevresel performanslarının YTZY'yi kabul ettikçe gelişeceğini iddia etmiştir. Bulanık küme teorisi ve DEMATEL yöntemini kullanarak sekiz kriter arasındaki etkili faktörleri incelemişlerdir. Mathiyazhagan vd. (2015), YTZY'nin benimsenmesine yönelik baskıları araştırmayı ve madencilik ve maden endüstrisi bağlamında AHP tekniği aracılı̆ıyla uzmanların görüşüne dayalı baskılar sıralamayı hedeflemişlerdir. Barari vd. (2012), tedarik zinciri varlıklarının kar maksimizasyonu amacı ile evrimsel oyun yaklaşımını kullanarak entegre ve bütüncül kavramsal çerçeve sağlamayı amaçlamıştır. Jamshidi vd. (2012) maliyet ve çevresel etkileri göz önüne alarak yeşil tedarik zinciri için çok objektif bir optimizasyon problemini çözmek için Taguchi yöntemi ile birlikte bir memetik algoritma kullanmıştır. Wang vd. (2011), çevresel yatırımlar için tasarım aşamasında alınan kararlarla ilgilenmiş ve toplam maliyet ile çevre etkisi arasındaki dengeyi temsil eden çok amaçlı bir optimizasyon modeli önermiştir. Yüce ve Mastrocinque (2015), yeşil tedarikçi seçimi problemini çözmek için Bulanık Analitik Hiyerarşi Süreci (AHP) ve Arılar Algoritması'nı birleştiren bir yaklaşım önermiştir. YTZY'yi ÇKKV yöntemlerini kullanarak tedarikçi değerlendirmeyip o firmanın fabrikalarını değerlendiren Rostamzadeh vd. (2015), ISO14001 sertifikasına sahip laptop hard diski üreten bir firmanın 4 fabrikası üzerinde belirlemiş olduğu YTZY kriterlerini Bulanık VIKOR yöntemini kullanarak incelemiştir. Firmanın fabrikalarını YTZY kriterlerine göre sıralamıştır. Bu çalışmada da Türk Otomotiv Ana Sanayi, YTZY'ye ait kriterler boyutunda incelenmiştir. Her otomotiv firmasının YTZY'ye ait bakış açısı farklı olduğundan Otomotiv Ana Sanayi'nde yer alan 11 otomotiv firmasında bulunan 40 uzman ile görüşülerek analiz yapılmıştır. Ayrıca genelden özele gidilerek Türk Otomotiv Ana Sanayi'nden alınan bilgi, ÇKKV yöntemlerini kullanarak bir firma üzerinde uygulanmıştır.

\section{Materyal ve Metot}

Bu çalışmanın temel amacı mutlak, bulanık ve sezgisel bulanık ÇKKV metotlarını kullanarak YTZY girişimlerine ait kriterleri Türk Otomotiv Ana Sanayi'nde kapsamlı bir şekilde incelemektir. Bu bağlamda bir model önerilmiştir. Önerilen modelin metodolojisi Şekil 1'de verilmiştir. Buna göre modelin ilk adımında karar vericilerin belirlenmesi bulunmaktadır. Bu adımda Türk Otomotiv Ana Sanayi'nde çalışmada yer alan 11 firma ve 40 uzman belirlenmiştir. íkinci adımda ise Ford OTOSAN'ın 4 fabrikası ve 4 uzman belirlenmiştir. Bir sonraki adımda YTZY ait kriterler literatürden derlenmiş ve karar vericiler tarafından gözden geçirilip tekrar düzenlenmiştir. Sonrasında oran ağırlıkları yöntemi kullanılarak her firmadaki karar vericiler tarafından kriterler ağılıklandırılmıştır. Devamında Ford OTOSAN'ın 4 fabrikası, 4 uzman tarafından konsensüs sağlanarak ve dilsel değerler kullanılarak değerlendirilmiştir. Ford OTOSAN'ın fabrikalarının sıralaması yani ağırlıklandırılması yapılmadan önce YTZY kriterlerini değerlendiren 11 firmanın önem ağırlıklarının eşit olup olmadığı sorgulanmıştır. Eşitlik söz konusu olduğu durumda her firmanın önem ağırlığı 1/11'dir. Ancak eşitlik olmadığı durumlar için 0 ile 1 arasında ve toplamı 1 olan sayılar türetilir ve uygulamaya devam edilir. Bu çalışmada 10 faklı senaryo türetilmiştir. Sonrasında mutlak sayıları, bulanık sayıları ve sezgisel bulanık sayıları içeren 8 ayrı metot kullanılarak, fabrikaların sıralamalarında meydana gelen değişimler incelenmiştir. Denemeler sonucunda Türk Otomotiv Ana Sanayi'nde yer alan Ford 
OTOSAN fabrikalarının YTZY kriterlerine göre değerlendirilmesinde istikrarlı bir şekilde aynı sıralamayı sağlayan metotlar, bu konuda en tutarlı metot olarak belirlenmiştir.

\section{Şekil 1: Önerilen modelin metodolojisi}

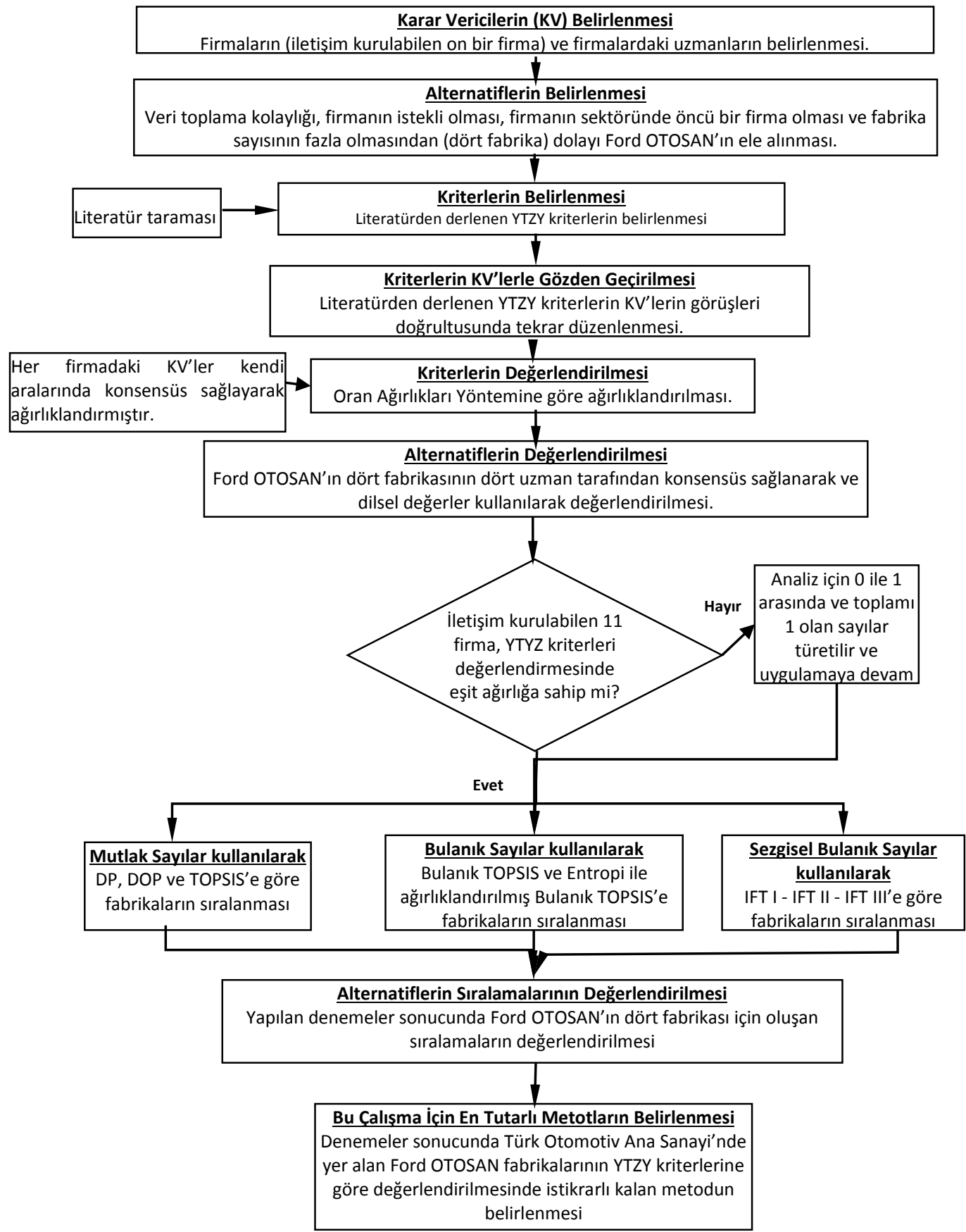




\subsection{Materyal}

Çalışmada kriterlerin düzenlenmesi ve ağırlıklandırılması için Karar Verici (KV) olarak yer alan firmalar aşağıda Tablo 1'de verilmiştir.

Tablo 1: Çalışmaya Katılan Türk Otomotiv Ana Sanayi'nde Yer Alan 11 Firma

\begin{tabular}{ll}
\hline Kod & Firma Adı \\
\hline \hline KV1 & Ford OTOSAN (Ford Otomotiv Sanayi A.Ş.) \\
KV2 & Mercedes-Benz Türk A.Ş. \\
KV3 & TOFAŞ Türk Otomobil Fabrikası A.Ş. \\
KV4 & Otokar Otomotiv ve Savunma Sanayi A.Ş. \\
KV5 & Karsan Otomotiv Sanayii ve Tic. A.Ş. \\
KV6 & RENAULT (MAis Motorlu Araçlar İmal ve Satış A.Ş.) \\
KV7 & Honda Türkiye A.Ş. \\
KV8 & Hyundai Assan Otomotiv Sanayi ve Ticaret A.Ş. \\
KV9 & TOYOTA Otomotiv Sanayi Türkiye A.Ş. \\
KV10 & TEMSA Ulaşım Araçları Sanayi ve Ticaret A.Ş. \\
KV11 & Türk Traktör ve Ziraat Makineleri A.Ş. \\
\hline
\end{tabular}

Tablo 1'de yer alan bu firmalar, ülkemiz Otomotiv Sanayi'ni uluslararası platformda temsil eden Otomotiv Sanayi Derneği'nin (OSD) üyeleridir. Bu firmaların çoğu farklı niteliklerde, Türkiye'nin 500 Büyük Sanayi Kuruluşu (iSO 500) arasında yer almaktadır.

Araştırmada kriterlerin düzenlenmesi ve ağırlıklandırılması için Tablo 1'de yer alan tüm firmalar kullanılmıştır. Ancak alternatif sıralamasında Ford OTOSAN ele alınmıştır. Ford OTOSAN, Türk otomotiv sektöründe ilk Ar-Ge çalışmalarını başlatan ve sektöründeki en büyük Ar-Ge merkezi yapılanmasına sahip olan firmadır. Ayrıca Türkiye'de sıfırdan araç ve motor tasarlayıp, test edebilen ve üretebilen de tek otomotiv firmasıdır. Ford OTOSAN'ın, Kocaeli'nde Gölcük (F1) ve Yeniköy fabrikaları (F2), Eskişehir Inönü'de kamyon (F3) ve motor fabrikaları (F4) olmak üzere dört üretim tesisi bulunmaktadır. Bununla beraber İstanbul Sancaktepe'de Yedek Parça Dağıtım Merkezi ve Sancaktepe Ar-Ge merkezi bulunmaktadır.

Söz konusu fabrikaların sıralaması Türk Otomotiv Ana Sanayi tarafından düzenlenen ve ağılıklandırılan YTZY kriterleri kullanılarak yapılmıştır. Kriterler Rostamzadeh vd. (2015) tarafından yapılan çalışmadan alınmış ve daha sonra Türk Otomotiv Ana Sanayi'ne göre tekrar düzenlenmiştir. Çalışmayı oluşturan kriterlerin 6 ana ve 30 alt kriterden oluştuğu görülmektedir. Bu kriterler kullanılarak 4 fabrikanın değerlendirilmesi ve sonuçta YTZY kriterlerine göre sıralaması yapılmaktadır. Altı ana kriter yeşil tasarım, yeşil satın alma, yeşil üretim, yeşil depolama, yeşil taşıma ve yeşil geri dönüşümden oluşmaktadır.

\subsection{Metot}

Araştırmada kriterlerin ağırlıklandırılması aşamasında Oran Ağırlıkları Tekniği kullanılmıştır. Ford OTOSAN fabrikalarının sıralanmasında ise mutlak sayılar, bulanık sayılar ve sezgisel bulanık sayıları içeren 8 ayrı metot kullanılmaktadır. Bunlardan Doğrusal Puanlama (DP), Doğrusal Olmayan Puanlama (DOP) ve Mutlak TOPSIS metodu, mutlak sayıları içermekte; Bulanık TOPSIS ve Entropi ile Ağılıklandırılmış Bulanık TOPSIS metodu ise bulanık sayıları içermektedir. Üç farklı Entropi ile ağırlıklandırılmış Sezgisel Bulanık TOPSIS metotları (IFT-I, IFTII, IFT-III) ise sezgisel bulanık sayıları içermektedir. Bu metotlar kullanılırken dilsel değerlendirmeler kullanılmaktadır. Aşağıda Tablo 2'de dilsel değerlendirmelerin metotlara göre karşılıkları verilmiştir. 
Tablo 2: Dilsel Değerlendirmelerin Karşılıkları

\begin{tabular}{|c|c|c|c|c|c|c|c|c|c|}
\hline \multirow{2}{*}{$\begin{array}{c}\text { Dilsel } \\
\text { Değerlendirme }\end{array}$} & \multirow[b]{2}{*}{ Semboller } & \multirow{2}{*}{$\begin{array}{c}\text { Doğrusal } \\
\text { Puanlama }\end{array}$} & \multirow{2}{*}{$\begin{array}{l}\text { Doğrusal } \\
\text { Olmayan } \\
\text { Puanlama }\end{array}$} & \multicolumn{3}{|c|}{ Üçgensel Bulanık Küme } & \multicolumn{3}{|c|}{ Sezgisel Bulanık Küme } \\
\hline & & & & Kötü & Orta & İyi & $\mu$ & $\mathbf{u}$ & $\pi$ \\
\hline Ç̧ok Kötü & ÇK & 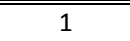 & 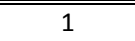 & 0.00 & 0.00 & 0.25 & 0.20 & 0.70 & 0.10 \\
\hline Kötü & $\mathrm{K}$ & 2 & 2 & 0.00 & 0.25 & 0.50 & 0.30 & 0.60 & 0.10 \\
\hline Orta & 0 & 3 & 5 & 0.25 & 0.50 & 0.75 & 0.45 & 0.35 & 0.20 \\
\hline İyi & $\mathrm{i}$ & 4 & 8 & 0.50 & 0.75 & 1.00 & 0.60 & 0.30 & 0.10 \\
\hline Çok İyi & çi & 5 & 10 & 0.75 & 1.00 & 1.00 & 0.80 & 0.10 & 0.10 \\
\hline
\end{tabular}

Kaynak: Wood, 2016, s. 599

Çalışmada kullanılan ÇKKV problemi için Karar Matrisi (KM) aşağıdaki gibidir:

$$
\begin{aligned}
& \begin{array}{llll}
F_{1} & F_{2} & \cdots & F_{n}
\end{array} \\
& K M=\begin{array}{c}
K_{1} \\
K_{2} \\
\vdots \\
K_{m}
\end{array}\left[\begin{array}{llll}
x_{11} & x_{12} & \cdots & x_{1 n} \\
x_{21} & x_{22} & \cdots & x_{2 n} \\
\vdots & \vdots & \vdots & \vdots \\
x_{m 1} & x_{m 2} & \cdots & x_{m n}
\end{array}\right]
\end{aligned}
$$

KM karar matrisi olmak üzere; $F_{j}=\left\{F_{1}, F_{2}, \ldots, F_{n}\right\}(j=1,2, \ldots, n)$ fabrikaların kümesini,

$$
K_{i}=\left\{K_{1}, K_{2}, \ldots, K_{m}\right\}(i=1,2, \ldots, m) \quad \text { Kriterlerin kümesini, }
$$

$W c_{i}=\left\{W c_{1}, W c_{2}, \ldots, W c_{m}\right\}(i=1,2, \ldots, m) \quad$ kriterlerin ağırlıkları kümesini ve

$W g_{k}=\left\{W g_{1}, W g_{2}, \ldots, W g_{l}\right\}(k=1,2, \ldots l)$ ise $l$ karar vericinin önem ağırlığını ifade etmektedir.

Bu araştırma için $n=4$ fabrika, $m=30$ kriter, $l=11$ firma olarak belirlenmiştir.

\subsubsection{Oran Ağırlıkları Tekniği}

Oran ağırlıkları atama/tahmin prosedüründe karar vericilerden kriterlerin göreli önemlerine göre sıralanmasından sonra, diğer tüm kriterlerin "en önemsiz" olarak görülen belirli bir kritere göre "ne kadar daha fazla önemli" olduğu bilgisi istenmektedir (Borcherding vd., 1995, s. 7). Bu prosedür şöyle gerçekleşmektedir (Edwards, 1977):

1. Adım: Kriterler önem sırasına göre sıralanmaktadır.

2. Adım: En az önemli (en önemsiz) kritere 1 değeri atanır. Sonra, diğer kriterlerin bu en az önemli olana oranla ne kadar daha fazla önemli oldukları belirlenerek, diğerlerine 1'den fazla değerler verilir.

3. Adım: 2. adımdaki işlem tüm kriterler için tamamlanınca, atanan bu ham ağırlıklar toplamlarına bölünerek normalize edilir:

$$
W_{c_{i}}=\frac{W_{c_{i}}^{*}}{\sum_{i=1}^{m} W_{c_{i}}^{*}}
$$

Burada, $W_{c_{i}}^{*}$ i. kriterin ham oran ağırlığıdır. $W c_{i}$, i'nci normalize edilmiş ağırlıktır.

\subsubsection{Doğrusal ve Doğrusal Olmayan Puanlama}

Doğrusal ve doğrusal olmayan puanlama, basitlik ve hesaplama kolaylığı nedeniyle karar vericiler tarafından tercih edilmektedir. Ancak daha fazla bilgi içeren daha karmaşık / sofistike 
metodolojilerle karşılaştırarak değerlendirmek de önemlidir. Bu yaklaşımlarda, dilsel değerlendirmeler (Tablo 2) için sayısal puanlar atanmıştır. Doğrusal yaklaşımda ÇK=1, K=2, $\mathrm{O}=3, \mathrm{i}=4$ ve Çi=5 iken, olumlu değerlendirmelere daha fazla ağıllık veren doğrusal olmayan yaklaşımda ise ÇK=1, $K=2, O=5, \dot{i}=8$ ve çi $=10$ olarak ifade edilmektedir. Daha sonra bu puanlar, fabrikaları (sütunlar) ve kriterleri (satırlar) ayırt etmeye yardımcı olan bilgileri ortaya çıkarmak için sütunların ve satırların toplamıyla birlikte matrisler olarak ifade edilmektedir. Matris biçiminde sütunların toplamları aşağıdaki gibidir (Wood, 2016:600-603):

$$
\tilde{F}_{j}=\sum_{i=1}^{m} x_{i j} ; \text { ile } i=1, \ldots, m ; j=1, \ldots, n
$$

$\widetilde{F}_{j}$, her j. Fabrika için ağırlıklandırılmamış kriter puanlarının toplamı olarak ifade edilmektedir.

Literatürde tanımlanabilir birçok puanlama sistemi karşımıza çıkmaktadır. Örneğin; olumsuz değerlendirmeyi negatif, olumlu değerlendirmeyi pozitif olarak puanlayan ÇK=-5, $\mathrm{K}=-$ 2.5, $\mathrm{O}=0, \mathrm{i}=+2.5$ ve Ç $\mathrm{i}=5$ gibi ölçeklerdir. Hem negatif hem pozitif sayıları içeren ölçek bu çalışmada kullanılmamıştır. Bu yaklaşımlarda ölçek kullanımı tamamen isteğe bağlı olarak yapılmaktadır. Amaç, sadece matematiksel hesaplamaları sağlayan sayısal bir temel oluşturmaktır. Hiçbir şekilde nicel bir analizi temsil etmemekle birlikte belirsizlikleri de ifade etmemektedirler. Burada önemli olan, kriter ağırlıklarını ve KV'lerin önem ağırlıklarını da hesaplamalara dahil etmektir. Bu hesaplamalar için matris formatı aşağıda verilmiştir:

$$
p_{j k}=\sum_{i=1}^{m} x_{i j} \times W c_{i} \times W g_{k} ; i=1, \ldots, m ; j=1, \ldots, n ; k=1, \ldots, l
$$

$p_{j k}$, k. karar vericinin önem ağırlığı ile j. fabrikanın ağırlıklandırılmış kriter puanlarının toplamı ifade etmektedir.

$$
\begin{aligned}
& \tilde{P}_{j}=\sum_{k=1}^{l} p_{j k} ; j=1, \ldots, n ; k=1, \ldots, l \\
& \tilde{P}_{j}, \text { j. fabrika için toplam ağırlı̆̆ı ifade etmektedir. }
\end{aligned}
$$

\subsubsection{TOPSIS Metodu}

TOPSIS metodolojisi ile doğrusal ve doğrusal olmayan puanlama yaklaşımları arasındaki fark, TOPSIS'in, her kriter değerlendirmesinde pozitif ideal ve negatif ideal çözüm uzaklığını dikkate alarak, negatif ideal çözümden olan uzaklığını en üst düzeye çıkararak, göreli yakınlık değerini (RC) dikkate almasıdır (Krohling ve Campanharo, 2011; Ghazanfari vd., 2014).

Eşitlik 1'deki karar matrisini boyutsuz bir matrise dönüştürmek için normalleştirme yapmak gerekmektedir. Her satırdaki (kriterler) matris elemanlarının, o sıradaki bütün elemanların karelerinin toplamının kareköküne bölünmesi ile o sıranın elemanları normalize edilmiş olmaktadır (rij). 


$$
r_{i j}=\frac{x_{i j}}{\sqrt{\sum_{j=1}^{n} x_{i j}^{2}}}, \quad i=1, \ldots, m ; j=1, \ldots, n
$$

$R$, normalize edilmiş karar matrisi olmak üzere;

$$
R=\left[r_{i j}\right]_{m x n}, i=1, \ldots, m ; j=1, \ldots, n
$$

Normalleştirilmiş karar matrisine Eşitlik (4) uygulanarak, önem ağıllıkları ( $W g$ ) hariç tutularak yalnızca kriter ağırlıkları $(W c$ ) dikkate alınarak ağırlıklandırılmış karar matrisi elde edilmekte ve Pozitif İdeal Çözüm $\left(A^{+}\right)$ve Negatif ìdeal Çözüm $\left(A^{-}\right)$olarak tanımlanmaktadır:

$$
A^{+}=\left(p_{1}^{+}, p_{2}^{+}, \ldots, p_{n}^{+}\right)
$$

$$
A^{-}=\left(p_{1}^{-}, p_{2}^{-}, \ldots, p_{n}^{-}\right)
$$

Burada;

$$
\begin{aligned}
& p_{i}^{+}=\max _{j}\left(p_{i j}\right), i=1, \ldots, m ; j=1, \ldots, n \\
& p_{i}^{-}=\min _{j}\left(p_{i j}\right), i=1, \ldots, m ; j=1, \ldots, n
\end{aligned}
$$

Daha sonra, her kriteri (i) için pozitif-ideal ve negatif-ideal çözümlerden normalleştirilmiş matristeki her elemanın Öklid uzaklığı hesaplanır ve her bir fabrika (j) için toplanır.

$$
\begin{aligned}
& d_{j}^{+}=\sqrt{\sum_{i=1}^{m}\left(p_{i}^{+}-p_{i j}\right)^{2}}, i=1, \ldots, m ; j=1, \ldots, n \\
& d_{j}^{-}=\sqrt{\sum_{i=1}^{m}\left(p_{i j}-p_{i}^{-}\right)^{2}}, i=1, \ldots, m ; j=1, \ldots, n
\end{aligned}
$$

Burada;

$d_{j}^{+} ;$pozitif ideal çözümden ( $A^{+}$) Öklid uzaklığı

$$
d_{j}^{-} \text {; negatif ideal çözümden ( } A^{-} \text {) Öklid uzaklığı }
$$

Daha sonra, her bir fabrikaya ilişkin toplam Öklid uzaklıkları, göreceli yakınlık indeksini (RCj) hesaplamak için kullanılmaktadır.

$$
R C_{j}=\frac{d_{j}^{-}}{d_{j}^{+}-d_{j}^{-}} ; j=1, \ldots, n
$$

Göreli yakınlık değeri büyüklüğü daha sonra fabrikaları sıralamak için kullanılmaktadır. En büyük göreli yakınlık değerine sahip fabrika, değerlendirilen tüm $m$ kriterlerinden, negatif 
ideal çözümden en uzakta ve dolayısıyla pozitif ideal çözümün en yakınında bulunduğu için 1 . sırada yer almaktadır.

Bu çalışmada sunulan TOPSIS analizi iki adımda gerçekleştirilmiştir. İlk adım, her karar vericinin için ayrı TOPSIS analizini içermektedir. İkinci adımda ise her bir karar vericiye ait $\mathrm{RC}_{\mathrm{j}}$ oranlarını kullanarak, her birine tanımlanmış önem ağırlıklarıyla ikinci bir TOPSIS analizini içermektedir. İkinci aşamada hesaplanan $\mathrm{RC}_{\mathrm{g}}$ oranı hem kriterleri hem de önem ağırlıklarını barındıran göreli yakınlık değeridir.

\subsubsection{Bulanık TOPSIS Metodu}

Bulanıklık, Tablo 2'teki dilsel değerlendirmeleri, üçgensel sayı kümelerine dönüştürerek problemdeki belirsizlik unsurunu benimsemektir. Üçgensel bulanık sayılar, ÇKKV'de belirsizlik ve öznellik (sübjektiflik) yakalamak için etkili bir yol sunmaktadır. Her değerlendirme bulanık kümeye ait yüksek, orta ve düşük sayıların üçlüsü olarak ifade edilen bulanık bir sayı ile temsil edilmektedir (Krohling ve Campanharo, 2011; Ghazanfari vd., 2014).

Bulanık sayıları içeren TOPSIS yönteminde, pozitif-ideal çözüm ve negatif ideal çözümde Öklid uzaklıklarının hesaplamalarındaki farklılık dışında, mutlak sayıları içeren TOPSIS yönteminde olduğu gibi Eşitlik (4)'ten Eşitlik (14)'e kadar aynısı uygulanmaktadır. Bulanık TOPSIS'te üçgensel bulanık sayıların kullanımından dolayı Eşitlik (12) ve Eşitlik (13) yerine aşağıda verilen Eşitlik (15) ve Eşitlik (16) kullanılmaktadır.

$$
\begin{aligned}
& d_{j}^{+}=\sqrt{\sum_{i=1}^{m}(1 / 3)\left[\left(p a_{i}^{+}-p a_{i j}\right)^{2}+\left(p b_{i}^{+}-p b_{i j}\right)^{2}+\left(p c_{i}^{+}-p c_{i j}\right)\right]}, i=1, \ldots, m ; j=1, \ldots, n \\
& d_{j}^{-}=\sqrt{\sum_{i=1}^{m}(1 / 3)\left[\left(p a_{i j}-p a_{i}^{-}\right)^{2}+\left(p b_{i j}-p b_{i}^{-}\right)^{2}+\left(p c_{i j}-p b_{i}^{-}\right)\right]}, i=1, \ldots, m ; j=1, \ldots, n
\end{aligned}
$$

Burada;

$d_{j}^{+}$; pozitif ideal çözümden ( $\left.A^{+}\right)$Öklid uzaklığı

$d_{j}^{-}$; negatif ideal çözümden ( $A^{-}$) Öklid uzaklığı

$a, b, c$; bulanık kümeye ait yüksek, orta ve düşük sayı üçlüsü.

Bulanık TOPSIS analizi, mutlak sayıları içeren TOPSIS analizinde olduğu gibi iki aşamada yürütülmektedir. Illk aşamada, her bir karar vericinin yani 11 firma tarafından belirlenen ağırlıklar ile oluşturulan 11 ayrı Bulanık TOPSIS analizi hesaplanmaktadır. İkinci aşamada ise, ilk aşamada türetilen her bir karar verici için $\mathrm{RC}_{\mathrm{j}}$ oranları kullanılarak TOPSIS analizi ile $\mathrm{RC}_{\mathrm{g}}$ oranları hesaplanmaktadır. İkinci aşamada hesaplanan $\mathrm{RC}_{\mathrm{g}}$ oranı hem kriter ağırlıklarını hem de önem ağırlıklarını içermektedir.

\subsubsection{Entropi Ağırlıklı Bulanık TOPSIS Metodu}

Bulanık TOPSIS yöntemine entropi uygulaması eklenerek, objektif entropi ağırlıkları elde edilmektedir. Bulanık üçgensel sayılar önce entropi ile ağırlıklandırılıp (yani, objektif ağırlıklandırma) sonrasında karar vericilerin kriter ağırlıkları ve önem ağırlıkları (yani, subjektif ağırlıklandırma) hesaplanarak sıralamalar yapılmaktadır. Burada uygulanan Entropi Ağırlıklı Bulanık TOPSIS Yöntemi, Wang vd. (2007) tarafından önerilen metodun bir uyarlamasıdır. 
Entropi değerini hesaplamak için öncelikle Eşitlik (17) kullanılarak karar matrisini oluşturan bulanık üçgensel sayılar mutlak sayılara dönüştürülmektedir:

$$
x_{i j}=\frac{a_{i j}+b_{i j}+c_{i j}}{3}, i=1, \ldots, m ; j=1, \ldots, n
$$

Daha sonra, elde edilen mutlak sayılar, her kriter için Eşitlik (18) kullanılarak normalize edilmektedir:

$$
r_{i j}=\frac{x_{i j}}{\sum_{j=1}^{n} x_{i j}}, i=1, \ldots, m ; j=1, \ldots, n
$$

Karar matrisindeki her kriter için entropi değeri $(e)$, Eşitlik (19) kullanılarak hesaplanmaktadır:

$$
e_{i}=-k \sum_{j=1}^{n}\left(r_{i j} * \ln r_{i j}\right), i=1, \ldots, m ; j=1, \ldots, n
$$

Burada; $k$ bir sabittir ve $k=(\ln (n))^{-1}$ şeklinde hesaplanmaktadır.

Daha sonra, her kriter için entropi değerler kümesi, $E\left(C_{i}\right)$, entropi ağırlıklarını hesaplamak için kullanılmaktadır $\left(W_{e}\right)$. Entropi değerler kümesi $1^{\prime}$ den çıkarılarak farkın derecesi hesaplanmaktadır.

$$
d_{i}=1-E\left(C_{i}\right), i=1, \ldots, m
$$

Fark derecesi, her bir kriterin değerlendirmesi arasındaki doğal kontrast yoğunluğunu ifade edilmektedir (Wang vd., 2007). $d_{i}$ 'nin göreli değeri ne kadar yüksekse, objektiflikte o kadar yüksektir. Daha sonra, her kriter i için entropi ağırlığı w, entropi ağıllıklarının kümesini oluşturmak üzere hesaplanır $\left(\mathrm{W}_{\mathrm{e}}\right)$ :

$$
w_{i}=\frac{d_{i}}{\sum_{i=1}^{m} d_{i}}, i=1, \ldots, m
$$

Oluşturulan entropi ağırlıkları kümesi; $W_{e}=\left(w_{1}, w_{2}, \ldots, w_{i}, \ldots, w_{m}\right)$

$$
\text { Burada; } w_{i} \geq 0, \quad \sum_{i=1}^{m} w_{i}=1
$$

Bulanık karar matrisi, entropi (objektif) ağılıkları ve karar vericinin (öznel) kriter ağırlıkları ile hesaplanmaktadır. Daha sonra Bulanık TOPSIS metodolojisinde olduğu gibi devam etmektedir.

\subsubsection{Entropi Ağırlıklı Sezgisel Bulanık TOPSıS Metotları}

Sezgisel Bulanık Kümeler (IFS), bir elemanın söz konusu kümeye ait olma derecesini $(\mu)$, ait olmama derecesini $(v)$ ve tereddüt indeksini $(\pi)$ içermektedir. Bu durum, kriterlerin dilsel değerlendirmelerini oluşturan bilgiyi, kesin olmayan bilgiyi ve tereddüdü etkin bir şekilde karakterize edebilmektedir. 
Atanassov (1999), X evreninde sezgisel bulanık sayılar kümesi olan A'yı şu şekilde tanımlamıştır:

$A=\left\{\left[x, \mu_{A}(x), v_{A}(x)\right] / x \in X\right\}$

Burada;

$\mu_{A}: X \rightarrow[0,1], v_{A}: X \rightarrow[0,1]$

Şu şartlar altında:

$0 \leq \mu_{A}(x)+v_{A}(x) \leq 1, \forall x \in X$

Bu nedenle, $\mu_{A}$ ya da $v_{A}$, 0 ya da 1 'e eşitse, A yalnızca mutlak sayılar kümesine dönüşmektedir. $\mu_{A}+v_{A}$ 'nın toplamı 1'den küçük olduğunda, $\pi_{A}$ 'nın değeri şu şekilde tanımlanmaktadır (Hung ve Chen, 2009):

$\pi_{A}(x)=1-\mu_{A}(x)-v_{A}(x)$

$\pi_{A}, x$ 'in $A$ 'ya olan tereddüt derecesi olarak tanımlanmaktadır. Yani, $x$ 'in $A$ 'nın üyesi olup olmadığına ilişkin değerlendirmedeki belirsizlik derecesini ifade etmektedir.

Sezgisel ortamda, entropi ölçütü, her kriterle ilişkili göreli değer içeriği hakkında bilgi vermektedir. IFT entropisini hesaplamak için önerilen ve uygulanan birkaç farklı yöntem bulunmaktadır. Bu çalışmada ise IFT için üç tür yöntem (IFT-I, IFT-II, IFT-III) uygulanmaktadır.

Birinci yöntemde (IFT-1), Hung ve Chen (2009) tarafından uygulanan De Luca ve Termini'nin (1972) kavramlarına dayanan Vlachos ve Sergiadis (2007) tarafından önerilen entropi uygulaması kullanılmaktadır. Entropi değeri aşağıdaki gibi hesaplanmaktadır:

Burada; $i=1, \ldots, m ; j=1, \ldots, n$

Ayrıca $(1 / n \ln 2)$ sabiti ile $0 \leq E\left(C_{i}\right) \leq 1$ sağlanmaktadır.

Entropi ağırlıklarını $W_{e}$ hesaplamak için Eşitlik (20) ve Eşitlik (21) kullanılmaktadır. Entropi ağırlıklı sezgisel bulanık karar matrisi $Z$, entropi ağırlıkları $W_{e}$ ile sezgisel bulanık karar matrisinin $D$ 'nin çarpımıdır.

$Z=W_{e} \otimes D=\left\lfloor\bar{x}_{i j}\right\rfloor$

Burada;

$\bar{x}_{i j}=\left[1-\left(1-\mu_{i j}\right)^{w i}, v_{i j} w i\right], i=1, \ldots, m ; j=1, \ldots, n$

IFS'yi ağırlıklandırmak için Eşitlik (28), Atanassov (1999) tarafından önerilmiştir. Eşitlik (28) ile sezgisel bulanık karar matrisi elde edilmektedir. Sonrasında, mutlak sayıları içeren TOPSIS yönteminde olduğu gibi Eşitlik (4)'den Eşitlik (14)'e kadar aynısı uygulanmaktadır. Ancak IFT-1' de Eşitlik (12) ve Eşitlik (13) yerine Eşitlik (15) ve Eşitlik (16) kullanılmaktadır.

İkinci yöntemde (IFT-2), Szmidt \& Kacprzyk (2001) tarafından önerilen değere dayalı bir entropi uygulaması kullanılmaktadır: 


$$
E\left(C_{i}\right)=\frac{1}{n} \sum_{j=1}^{n} \frac{\min \left(\mu_{i j}\left(C_{i}\right), v_{i j}\left(C_{i}\right)\right)+\pi_{i j}\left(C_{i}\right)}{\max \left(\mu_{i j}\left(C_{i}\right), v_{i j}\left(C_{i}\right)\right)+\pi_{i j}\left(C_{i}\right)}, i=1, \ldots, m ; j=1, \ldots, n
$$

Daha sonra, IFT-2 entropi değerleri Eşitlik (30) ile normalize edilmektedir:

$$
h_{i}=\frac{E\left(C_{i}\right)}{\max \left[E\left(C_{i}\right)\right]}, i=1, \ldots, m
$$

Burada; $h_{i}$, IFT-2 metodu için normalize edilmiş karar matrisini, $E\left(C_{i}\right)$ kriterlerin entropi değerlerinin kümesini ifade etmektedir. $h_{i}$ değeri her kriter için en yüksek 1'e, en düşük 0’a eşittir.

Her kriter i için entropi ağırlıkları Eşitlik (21) kullanılarak, IFT-1 metodunda olduğu gibi hesaplanmaktadır. Bu ağırlıklar daha sonra Eşitlik (28) kullanılarak IFT-2 karar matrisine uygulanmaktadır. Sonrasında, mutlak sayıları içeren TOPSIS yönteminde olduğu gibi Eşitlik (4)'ten Eşitlik (14)'e kadar aynısı uygulanmaktadır. Ancak IFT-2' de Eşitlik (12) ve (13) yerine aşağıda Eşitlik (31) ve Eşitlik (32) kullanılmaktadır.

$$
\begin{aligned}
& d_{j}^{+}=\sum_{i=1}^{m} \max \left[\left(p \mu_{i}^{+}-p \mu_{i j}\right),\left(p v_{i}^{+}-p v_{i j}\right)\right], i=1, \ldots, m ; j=1, \ldots, n \\
& d_{j}=\sum_{i=1}^{m} \max \left[\left(p \mu_{i j}-p \mu_{i}^{-}\right),\left(p v_{i j}-p v_{i}^{-}\right)\right], i=1, \ldots, m ; j=1, \ldots, n
\end{aligned}
$$

$d_{j}^{+}$; pozitif ideal çözümden ( $A^{+}$) Öklid uzaklı̆̆ı

$d_{j}^{-}$; negatif ideal çözümden ( $A^{-}$) Öklid uzaklığı

$p \mu_{i}^{+}$ve $p v_{i}^{+}$, kriterlerin maksimum ağırlıklı değerleri.

$p \mu_{i}^{-}$ve $p v_{i}^{-}$, kriterlerin minimum ağılıklı değerleri.

Üçüncü yöntem (IFT-3), IFT-1 ile aynı metodoloji kullanılmakta, ancak Ye (2010) tarafından önerilen yöntemle entropi hesaplaması değişmektedir. IFT-1 metodolojisindeki Eşitlik (26), aşağıda Eşitlik (33) ile değiştirilmektedir:

$$
E\left(C_{i}\right)=\frac{1}{m} \sum_{j=1}^{n}\left\{\left\{\sin \frac{\pi \times\left[1+\mu_{i j}\left(C_{i}\right)-v_{i j}\left(C_{i}\right)\right]}{4}+\sin \frac{\pi \times\left[1-\mu_{i j}\left(C_{i}\right)-v_{i j}\left(C_{i}\right)\right]}{4}\right\} \times \frac{1}{\sqrt{2}-1}\right\}
$$

Burada; $i=1, \ldots, m ; j=1, \ldots, n$

$1 /(\sqrt{2}-1)$ sabiti ile $0 \leq E\left(C_{i}\right) \leq 1$ sağlanmaktadır. $\pi$, burada tereddütlük indeksi değil matematiksel sabiti ifade etmektedir. IFT-1 metodolojisindeki adımlar daha sonra IFT-3 metodolojisinde de tekrarlanmaktadır.

Sezgisel Bulanık TOPSIS metotları, diğer metotlarda da olduğu gibi iki aşamada yürütülmektedir. Illk aşamada, her bir karar vericinin yani 11 firma tarafından belirlenen ağırlıklar ile oluşturulan 11 ayrı Bulanık TOPSIS analizi hesaplanmaktadır. İkinci aşamada ise, 
ilk aşamada türetilen her bir karar verici için $\mathrm{RC}_{\mathrm{j}}$ oranları kullanılarak TOPSIS analizi ile $\mathrm{RC}_{\mathrm{g}}$ oranları hesaplanmaktadır. İkinci aşamada hesaplanan $\mathrm{RC}_{\mathrm{g}}$ oranı hem kriter ağılıklarını hem de önem ağırlıklarını içermektedir.

\section{Bulgular ve Tartışmalar}

YTZY kriterleri. Rostamzadeh vd. (2016) tarafından bir laptop firmasında uygulaması yapılan çalışmadan alınmıştır. Ancak çalışmada ele alınan bu kriterler Türk Otomotiv Ana Sanayi'ne uygunluğu açısından uzmanlar tarafından tekrar değerlendirilmiştir. Bu değerlendirme Tablo 3' de verilmiştir.

Tablo 3: Türk Otomotiv Ana Sanayi İçin Tekrar Değerlendirilip Son Halini Alan Kriterler

\begin{tabular}{|c|c|c|}
\hline \multicolumn{3}{|r|}{ KRITERLER } \\
\hline 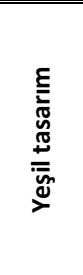 & $\begin{array}{l}\mathrm{K} 1 \\
\mathrm{~K} 2 \\
\mathrm{~K} 3 \\
\mathrm{~K} 4\end{array}$ & $\begin{array}{l}\text { Materyal/Enerji tüketimini azaltan ürün tasarımının yapılması } \\
\text { Materyallerin tekrar kullanımı (reuse), geri dönüşümünü (recycle), tekrar kazanımını (recovery) } \\
\text { sağlayan ürün tasarımının yapılması } \\
\text { Zararlı ürünlerin ve/veya üretim prosesinin kullanımının azaltılmasını veya kullanımından } \\
\text { kaçınılmasını sağlayan ürünlerin tasarımının yapılması } \\
\text { En fazla enerji tasarrufu sağlayacak şekilde kolayca kullanılabilecek ürünlerin tasarımının } \\
\text { yapııması } \\
\text { Eko-tasarım için müşterilerle iş birliği yapılması }\end{array}$ \\
\hline 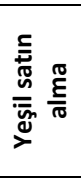 & $\begin{array}{r}\text { K6 } \\
\text { K7 } \\
\text { K8 } \\
\text { K9 } \\
\text { K10 }\end{array}$ & $\begin{array}{l}\text { Çevresel kriterleri dikkate alan tedarikçilerin seçilmesi } \\
\text { Çevre-dostu hammaddelerin satın alınması } \\
\text { Çevresel önlemler almaları için tedarikçilere baskı yapılması } \\
\text { Tedarikçi çevre yönetim sisteminin olması } \\
\text { Tedarikçilerin çevresel iç denetim mekanizmasının olması }\end{array}$ \\
\hline 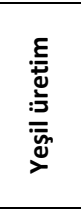 & $\begin{array}{l}\text { K11 } \\
\text { K12 } \\
\text { K13 } \\
\text { K14 } \\
\text { K15 } \\
\text { K16 }\end{array}$ & $\begin{array}{l}\text { Yeniden üretim (re-manufacturing) ve yalın üretimin (lean production) olması } \\
\text { Temiz üretimin olması } \\
\text { Atık oranının azaltımı ve ürün kalitesini yükseltilmesi } \\
\text { Daha iyi (gelişmiş) kapasite kullanılması } \\
\text { Zamanında teslim edilen ürünlerin miktarının artırılması } \\
\text { Müşterilerle çalışılarak çevresel etkiyi azaltacak faaliyetlerde bulunulması }\end{array}$ \\
\hline 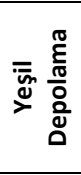 & $\begin{array}{l}\text { K17 } \\
\text { K18 } \\
\text { K19 } \\
\text { K20 } \\
\text { K21 }\end{array}$ & $\begin{array}{l}\text { Çevre dostu paketleme yapılması } \\
\text { Ürün stok seviyelerinin azaltılması } \\
\text { Fazla stokların satılması } \\
\text { İmalata girecek hammaddelerin/parçaların depolanması } \\
\text { Atıl durumdaki ekipmanların değerlendirilmesi }\end{array}$ \\
\hline 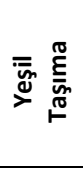 & $\begin{array}{l}\mathrm{K} 22 \\
\mathrm{~K} 23 \\
\mathrm{~K} 24 \\
\mathrm{~K} 25 \\
\mathrm{~K} 26\end{array}$ & $\begin{array}{l}\text { Çevre dostu taşımacılık yapılması } \\
\text { Çevre dostu dağıtım yapılması } \\
\text { Eko-verimlilik sağlayan taşımacılık filosu kullanılması } \\
\text { Düşük salınım içeriği olan yakıtların kullanııması } \\
\text { Yakıt tüketimini azaltıcı yönde sürüş alışkanlıklarının geliştirilmesi için destek verilmesi }\end{array}$ \\
\hline 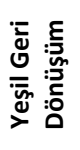 & $\begin{array}{l}\text { K27 } \\
\text { K28 } \\
\text { K29 } \\
\text { K30 }\end{array}$ & $\begin{array}{l}\text { Tedarikçilere kendi çevre yönetim sistemini kurması için yardım edilmesi } \\
\text { Ömrünü tamamlamış ürünlerin geri kazanılması } \\
\text { Yenilenebilir enerji kaynaklarının kullanılması } \\
\text { Atıkların başka fabrikalar tarafından değerlendirilmesi }\end{array}$ \\
\hline
\end{tabular}

\subsection{YTZY Kriterlerinin Ağırlıklandırılması}

Kriterlerin ağırlıklandırımasında, oran ağırlıkları tekniği kullanılmıştır. Ağılıklar hesaplanırken Eşitlik (2)'den yararlanılmıştır. Tablo 4'te tüm alt kriterlerin global ağırlıkları verilmiştir. Bu kriterlerin arasında ağırlıkları yüksek olanlar yeşil geri dönüşüm ve yeşil tasarımda yoğunlaşmıştır. Bunlar; yenilenebilir enerji kaynaklarının kullanılması, ömrünü tamamlamış ürünlerin geri kazanımı, tedarikçilere kendi çevre yönetim sistemini kurması için 
yardım edilmesi, zararlı ürünlerin ve/veya üretim prosesinin kullanımının azaltılmasını veya kullanımından kaçınıımasını sağlayan ürünlerin tasarımının yapılması, materyallerin tekrar kullanımı (reuse), geri dönüşümünü (recycle), tekrar kazanımını (recovery) sağlayan ürün

tasarımının yapılması ve materyal/enerji tüketimini azaltan ürün tasarımının yapılmasıdır. Bu kriterlerin arasında ağılığı düşük olanlar ise ürün stok seviyelerinin azaltılması, fazla stokların satılması. imalata girecek hammaddelerin/parçaların depolanması, atıl durumdaki ekipmanların değerlendirilmesi ve müşterilerle çalışılarak çevresel etkiyi azaltacak

faaliyetlerde bulunulması olarak belirlenmiştir.

Tablo 4: Alt Kriterlerin Global Ağırlıkları

\begin{tabular}{|c|c|c|c|c|c|c|c|c|c|c|c|c|c|c|}
\hline \multirow{2}{*}{\multicolumn{2}{|c|}{ Kriterler }} & \multicolumn{11}{|c|}{ GLOBAL AĞIRLIKLAR } & \multirow{3}{*}{$\begin{array}{l}\text { G.O. } \\
0.039\end{array}$} & \multirow{3}{*}{$\begin{array}{l}\text { A.O. } \\
0.041\end{array}$} \\
\hline & & KV1 & KV2 & KV3 & KV4 & KV5 & KV6 & KV7 & KV8 & KV9 & KV10 & KV11 & & \\
\hline \multirow{5}{*}{ 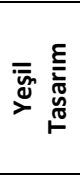 } & . & 0.044 & 0.038 & 0.041 & 0.066 & 0.027 & 0.042 & 0.019 & 0.054 & 0.034 & 0.033 & 0.050 & & \\
\hline & $\mathrm{K}^{2}$ & 0.055 & 0.038 & 0.041 & 0.040 & 0.020 & 0.062 & 0.039 & 0.043 & 0.042 & 0.033 & 0.050 & 0.041 & 0.042 \\
\hline & K3 & 0.055 & 0.048 & 0.041 & 0.040 & 0.034 & 0.062 & 0.039 & 0.054 & 0.042 & 0.033 & 0.050 & 0.044 & 0.045 \\
\hline & K4 & 0.044 & 0.038 & 0.033 & 0.053 & 0.027 & 0.042 & & & & & & & \\
\hline & K5 & 0.011 & 0.038 & 0.033 & 0.033 & 0.017 & 0.055 & 0.031 & 0.054 & 0.034 & 0.033 & 0.025 & 0.030 & 0.033 \\
\hline \multirow{5}{*}{ 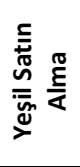 } & $K G$ & 0.049 & 0.040 & 0.022 & .029 & 30 & 25 & & & & & & & \\
\hline & K7 & 0.049 & 0.040 & 0.022 & 0.020 & 0.024 & 0.025 & 0.031 & 0.043 & 0.030 & 0.033 & & 32 & 3 \\
\hline & K8 & 0.039 & 0.040 & 0.017 & 0.020 & 0.024 & 0.019 & 0.025 & 0.043 & 0.030 & 0.033 & 25 & 7 & 29 \\
\hline & K9 & 0.024 & 0.040 & 0.017 & 0.015 & 0.024 & 0.019 & & 0.0 & 0. & & & & \\
\hline & K10 & 0.024 & 0.040 & 0.017 & 0.010 & 0.024 & 0.019 & 0. & 0.043 & 0.030 & 0.033 & 25 & 25 & 027 \\
\hline \multirow{6}{*}{ 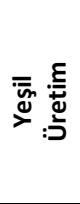 } & & 0.048 & 0.033 & 0.0 & 0.015 & 0.046 & 0.024 & & 0. & & & & & \\
\hline & $\mathrm{K}$ & 0.048 & 0.033 & 0.033 & 0.020 & 0.046 & 0.015 & 0. & 0.022 & 0.038 & 0.028 & & & 0.033 \\
\hline & & 0.038 & 0.033 & 0.0 & 0.020 & & & & & & & & & \\
\hline & K14 & 0.024 & 0.033 & 0.041 & 0.020 & 0.046 & 0.015 & 0. & $0 . C$ & 0.019 & & & & \\
\hline & & 0.019 & 0.0 & 0.0 & 0.0 & 0.0 & 0. & & & & & & & \\
\hline & $\rightarrow$ & 0.010 & 0.033 & 0.033 & 0.015 & 0.019 & 0.024 & 0. & 0.0 & 0.030 & 0.028 & & & \\
\hline \multirow{5}{*}{$\frac{\bar{c}}{\overline{\bar{d}}} \frac{\frac{\pi}{\pi}}{\frac{\pi}{0}}$} & & & & 0.0 & & & & & & & & & 0. & U. \\
\hline & & 0.007 & 0.017 & 0.029 & 0.037 & 0.029 & 0.020 & & & 0 & & & & \\
\hline & & 0.007 & 0.003 & 0.029 & 0.025 & 0.036 & 0.020 & & & 0. & & & & \\
\hline & K20 & 0.033 & 0.020 & 0.029 & 0.025 & 0.014 & 0.020 & 0. & 0.0 & 0.027 & 0.033 & 20 & & 0.024 \\
\hline & & 0.033 & 0.003 & 0.029 & 0.050 & 0.018 & 0.020 & & 0.0 & 0.011 & 0.033 & & & 0.024 \\
\hline \multirow{5}{*}{ 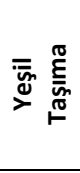 } & $\mathrm{K} 22$ & 0.034 & 0.027 & 0.026 & 0.049 & 0.031 & 0.042 & 0.030 & 0.027 & 0.030 & 0.033 & 0. & & 32 \\
\hline & & 0.034 & 0.027 & 0.026 & 0.049 & 0.013 & 0.042 & 0.030 & 0.027 & 0.030 & 0.033 & & & \\
\hline & K24 & 0.034 & 0.027 & 0.026 & 0.039 & 0.031 & 0.042 & 0.030 & 0.027 & 0.030 & 0.033 & 0.020 & & 0.0 \\
\hline & K25 & 0.042 & 0.027 & 0.026 & 0.024 & 0.031 & 0.067 & 0.030 & 0.034 & 0.030 & 0.033 & & & 0.033 \\
\hline & K26 & 0.042 & 0.027 & 0.039 & 0.024 & 0.019 & 0.017 & 0.030 & 0.034 & 0.030 & 0.033 & 0.020 & 0.027 & 0.029 \\
\hline \multirow{4}{*}{ 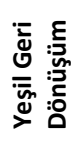 } & K27 & 0.026 & 0.044 & 0.046 & 0.033 & 0.136 & 0.021 & 0.046 & 0.044 & 0.049 & 0.042 & 0.033 & 0.042 & 0.047 \\
\hline & $\mathrm{K} 28$ & 0.052 & 0.056 & 0.061 & 0.053 & 0.045 & 0.042 & 0.046 & 0.056 & 0.049 & 0.042 & 0.067 & 0.051 & 0.052 \\
\hline & K29 & 0.052 & 0.056 & 0.061 & 0.066 & 0.045 & 0.084 & 0.046 & 0.056 & 0.062 & 0.042 & 0.067 & 0.057 & 0.058 \\
\hline & K30 & 0.010 & 0.044 & 0.046 & 0.033 & 0.023 & 0.063 & 0.046 & 0.044 & 0.025 & 0.042 & 0.033 & 0.034 & 0.037 \\
\hline
\end{tabular}

\subsection{Ford OTOSAN Fabrikalarının Değerlendirilmesi}

Ford OTOSAN'nın 4 fabrikası, mutlak sayılar- bulanık sayılar- sezgisel bulanık sayılar kullanılarak sekiz ayrı metotla, belirlenen YTZY kriterlerine göre göreceli olarak değerlendirilmiştir. Bu metotlar kullanılmadan önce fabrikalar Tablo 2'ye göre dilsel olarak değerlendirilmiştir. Bu değerlendirme fabrikalarda çalışan yönetici düzeyinde dört uzman tarafından konsensüs sağlayarak yapılmıştır. Yapılan dilsel değerlendirme Tablo 5 'te verilmiştir. 
Eskişehir Osmangazi Üniversitesi ïBF Dergisi

Tablo 5: Ford OTOSAN Fabrikalarının Dilsel Değerlendirmeleri

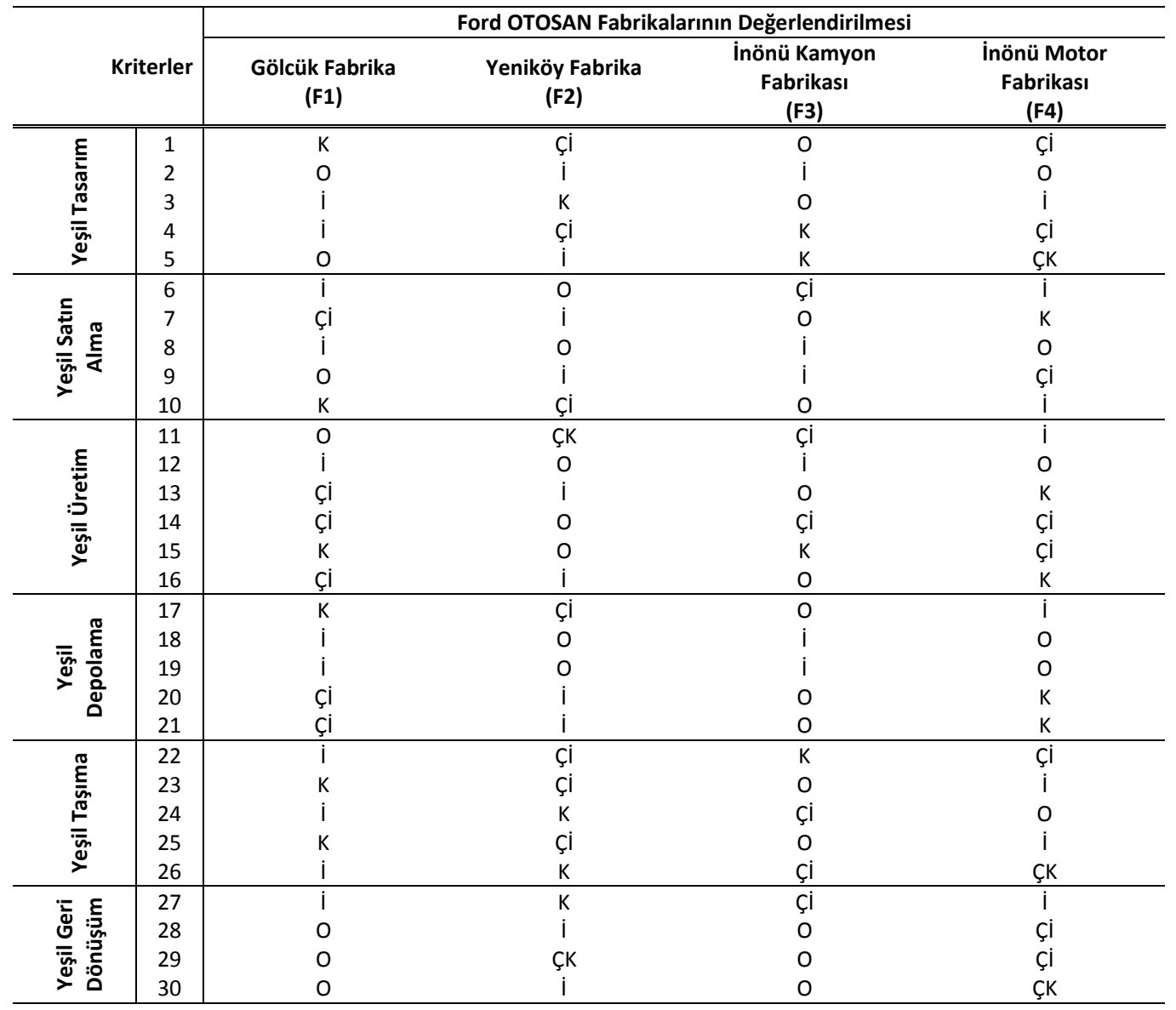

ÇK:Çok Kötü. K:Kötü. O:Orta. i:ìyi. Çi:Çok İyi

\subsection{Mutlak Sayılar Kullanılarak Yapılan Değerlendirme}

Burada doğrusal-doğrusal olmayan puanlama ve TOPSIS olmak üzere üç farklı metot kullanılmıştır. Doğrusal ve doğrusal olmayan puanlama, Tablo 2'de yapılan dilsel değerlendirmelerin karşılıkları alınarak yapılmıştır. Doğrusal puanlama için doğrusal karşılıklar, doğrusal olmayan için doğrusal olmayan karşılıklar kullanılmıştır. Böylelikle Eşitlik (3) kullanılarak doğrusal-doğrusal olmayan puanlama matrisi oluşturulmuştur. Bu matris Tablo 6' da verilmiştir. Tablo 6 incelendiğinde toplam puanlamadaki sıralamanın hem doğrusal hem de doğrusal olmayan ağırlıklandırılmamış puanlama için değişmediği görülmektedir. Her ikisi içinde Ford OTOSAN fabrikalarında sıralama F2>F1>F3>F4 şeklindedir. Bu sıralamalar, dilsel değerlendirmelere karşıık gelen sayıların farklılarından dolayı değişebilirdi. Ancak yapılan değerlendirmeler dört fabrika için çok yakın olduğu için bir değişiklik olmamıştır. Ayrıca bu tablodaki kriterler ile kriterlerin önem değerine bakıldığında farklılıklar görülmektedir. En 
yüksek puanlamaya sahip olan kriterler sırasıyla K6, K9 ve K4'tür. Bunlar; çevresel kriterleri dikkate alan tedarikçilerin seçilmesi, tedarikçi çevre yönetim sisteminin olması, en fazla enerji tasarrufu sağlayacak şekilde kolayca kullanılabilecek ürünlerin tasarımının yapılması şeklinde belirlenmiştir. En düşük puanlamaya sahip olan kriterler ise sırasıyla K15, K30, K29 ve K26'dır. Bunlar; zamanında teslim edilen ürünlerin miktarının artırılması, atıkların başka fabrikalar tarafından değerlendirilmesi, yenilenebilir enerji kaynaklarının kullanılması ve yakıt tüketimini azaltıcı yönde sürüş alışkanlıklarının geliştirilmesi için destek verilmesi olarak belirlenmiştir. Örneğin; K29 önem ağırlığı olarak en yüksek değere sahiptir. Ancak, doğrusal-doğrusal olmayan puanlamada en düşük ikinci değerdir. Bunun gibi örneklerin nedeni; YTZY konusunda olması beklenen ile gerçekleşen durumu arasındaki farktır. Çok önemli olarak görülen kriterler her zaman istenildiği kadar gerçekleştirilemeyebilir.

Tablo 6: Doğrusal ve Doğrusal Olmayan Puanlama Matrisleri

\begin{tabular}{|c|c|c|c|c|c|c|c|c|c|c|c|}
\hline \multirow[b]{2}{*}{ Ana Kriterler } & \multirow[b]{2}{*}{ Alt Kriterler } & \multicolumn{5}{|c|}{$\begin{array}{c}\text { Karar vericilerin değerlendirmelerinin } \\
\text { doğrusal puanları }\end{array}$} & \multicolumn{5}{|c|}{$\begin{array}{c}\text { Karar vericilerin değerlendirmelerinin } \\
\text { doğrusal olmayan puanları }\end{array}$} \\
\hline & & F1 & F2 & F3 & F4 & $\begin{array}{l}\text { Doğrusal } \\
\text { Toplam }\end{array}$ & F1 & F2 & F3 & F4 & $\begin{array}{c}\text { Doğrusal } \\
\text { Olmayan } \\
\text { Toplam }\end{array}$ \\
\hline \multirow{5}{*}{ Yeşil tasarım } & 1 & 2 & 5 & 3 & 5 & 15 & 2 & 10 & 5 & 10 & 27 \\
\hline & 2 & 3 & 4 & 4 & 3 & 14 & 5 & 8 & 8 & 5 & 26 \\
\hline & 3 & 4 & 2 & 3 & 4 & 13 & 8 & 2 & 5 & 8 & 23 \\
\hline & 4 & 4 & 5 & 2 & 5 & 16 & 8 & 10 & 2 & 10 & 30 \\
\hline & 5 & 3 & 4 & 2 & 1 & 10 & 5 & 8 & 2 & 1 & 16 \\
\hline \multirow{5}{*}{$\begin{array}{l}\text { Yeşil Satın } \\
\text { Alma }\end{array}$} & 6 & 4 & 3 & 5 & 4 & 16 & 8 & 5 & 10 & 8 & 31 \\
\hline & 7 & 5 & 4 & 3 & 2 & 14 & 10 & 8 & 5 & 2 & 25 \\
\hline & 8 & 4 & 3 & 4 & 3 & 14 & 8 & 5 & 8 & 5 & 26 \\
\hline & 9 & 3 & 4 & 4 & 5 & 16 & 5 & 8 & 8 & 10 & 31 \\
\hline & 10 & 2 & 5 & 3 & 4 & 14 & 2 & 10 & 5 & 8 & 25 \\
\hline \multirow{6}{*}{ Yeşil Üretim } & 11 & 3 & 1 & 5 & 4 & 13 & 5 & 1 & 10 & 8 & 24 \\
\hline & 12 & 4 & 3 & 4 & 3 & 14 & 8 & 5 & 8 & 5 & 26 \\
\hline & 13 & 5 & 4 & 3 & 2 & 14 & 10 & 8 & 5 & 2 & 25 \\
\hline & 14 & 3 & 3 & 4 & 3 & 13 & 5 & 5 & 8 & 5 & 23 \\
\hline & 15 & 2 & 3 & 2 & 3 & 10 & 2 & 5 & 2 & 5 & 14 \\
\hline & 16 & 5 & 4 & 3 & 2 & 14 & 10 & 8 & 5 & 2 & 25 \\
\hline \multirow{5}{*}{$\begin{array}{c}\text { Yeşil } \\
\text { Depolama }\end{array}$} & 17 & 2 & 5 & 3 & 4 & 14 & 2 & 10 & 5 & 8 & 25 \\
\hline & 18 & 4 & 3 & 4 & 3 & 14 & 8 & 5 & 8 & 5 & 26 \\
\hline & 19 & 4 & 3 & 4 & 3 & 14 & 8 & 5 & 8 & 5 & 26 \\
\hline & 20 & 5 & 4 & 3 & 2 & 14 & 10 & 8 & 5 & 2 & 25 \\
\hline & 21 & 5 & 4 & 3 & 2 & 14 & 10 & 8 & 5 & 2 & 25 \\
\hline \multirow{5}{*}{ Yeşil Taşıma } & 22 & 4 & 5 & 2 & 5 & 16 & 5 & 8 & 2 & 10 & 25 \\
\hline & 23 & 2 & 5 & 3 & 4 & 14 & 2 & 10 & 5 & 8 & 25 \\
\hline & 24 & 4 & 2 & 5 & 3 & 14 & 8 & 2 & 10 & 5 & 25 \\
\hline & 25 & 2 & 5 & 3 & 4 & 14 & 2 & 10 & 5 & 8 & 25 \\
\hline & 26 & 4 & 2 & 5 & 1 & 12 & 8 & 2 & 10 & 1 & 21 \\
\hline \multirow{4}{*}{$\begin{array}{l}\text { Yeşil Geri } \\
\text { Dönüşüm }\end{array}$} & 27 & 4 & 2 & 5 & 4 & 15 & 8 & 2 & 10 & 8 & 28 \\
\hline & 28 & 3 & 4 & 3 & 5 & 15 & 5 & 8 & 5 & 10 & 28 \\
\hline & 29 & 3 & 1 & 3 & 5 & 12 & 5 & 1 & 5 & 10 & 21 \\
\hline & 30 & 3 & 4 & 3 & 1 & 11 & 5 & 8 & 5 & 1 & 19 \\
\hline \multicolumn{2}{|c|}{ Toplam puan } & 105 & 106 & 103 & 99 & & 187 & 193 & 184 & 177 & \\
\hline
\end{tabular}

Doğrusal ve doğrusal olmayan puanlamalar belirlendikten sonra 11 karar verici firma tarafından belirlenen global kriter ağırlıkları (Tablo 4) ile Eşitlik (4)-(5) kullanılarak 
puanlamalar ağırlıklandırımıştır. Ağılıklandırılmış doğrusal ve doğrusal olmayan puanlama değerlendirmelerin özeti aşağıda Tablo 7' de verilmiştir.

Tablo 7' de karar vericilerin farklı kriter ağılıklandırmalarının uygulanması nedeniyle farklı sıralamalar söz konusu olmaktadır. Ağırlıklı doğrusal puanlamada F2>F4>F1>F3 olarak, ağırlıklı doğrusal olmayan puanlamada $\mathrm{F} 4>\mathrm{F} 2>\mathrm{F} 3>\mathrm{F} 1$ olarak sıralamalar oluşmaktadır. Doğrusal ağırlıklandırılmış puanlamada da ağırlıklandırılmamış puanlamada da F2 ilk sıradadır. Doğrusal olmayan ağırlıklandırılmamış puanlamada F2 birinci, F4 ise son sıradadır. Ancak ağılıklandırılmış puanlamada F4 ilk sıradadır. Bunların temel on bir KV'nin kriterleri sıralamadaki farklılıklarıdır. Doğrusal skorlamada KV, KV4, KV6, KV8 ve KV10; F2'yi birinci sırada ağırlıklandırmıştır. Doğrusal olmayan puanlamada ise KV1, KV2, KV9 ve KV11; F4 'ü diğer fabrikalara göre daha yüksek düzeyde ağırlıklandırmıştır.

Özetle, ağırlıklı doğrusal puanlamada Ford OTOSAN'ın Yeniköy Fabrikası'nın (F2) YTZY konusunda daha iyi olduğu ancak, ağırlıklı doğrusal olmayan puanlamaya göre İnönü Motor Fabrikası (F4) YTZY konusunda diğer fabrikalara göre daha etkili olduğu söylenebilmektedir.

Diğer yöntemler (TOPSIS, Bulanık TOPSIS, Entropi Ağılıklı Bulanık TOPSIS, IFT-1, IFT-2 ve IFT-3) için oluşturulan sıralamalar Tablo 7'de olduğu gibi gerekli formülasyonlar kullanılarak yapılmıştır. 
Tablo 7: Ağırlıklandırılmış Doğrusal ve Doğrusal Olmayan Puanlama Değerlendirmeleri

\begin{tabular}{|c|c|c|c|c|c|c|c|c|c|c|c|c|c|c|}
\hline \multicolumn{2}{|c|}{ Doğrusal skorlama } & \multicolumn{13}{|c|}{ Her karar verici için ağırlıklandırılmış kriter toplamları } \\
\hline Fabrikalar & $\begin{array}{l}\text { Ağırlıklandırı- } \\
\text { mamış toplam } \\
\text { skor }\end{array}$ & $\begin{array}{c}\mathrm{KV} 1 \\
(\mathrm{X} \times \mathrm{Wc})\end{array}$ & $\begin{array}{c}\mathrm{KV} 2 \\
(\mathrm{X} \times \mathrm{Wc})\end{array}$ & $\begin{array}{c}\mathrm{KV} 3 \\
(\mathrm{X} \times \mathrm{Wc})\end{array}$ & $\begin{array}{c}\text { KV4 } \\
(X \times W c)\end{array}$ & $\begin{array}{c}\mathrm{KV} 5 \\
(\mathrm{X} \times \mathrm{Wc})\end{array}$ & $\begin{array}{c}\mathrm{KV6} \\
(\mathrm{X} \times \mathrm{Wc})\end{array}$ & $\begin{array}{c}\mathrm{KV7} \\
(\mathrm{X} \times \mathrm{Wc})\end{array}$ & $\begin{array}{c}\mathrm{KV8} \\
(\mathrm{X} \times \mathrm{Wc})\end{array}$ & $\begin{array}{c}\mathrm{KV9} \\
(\mathrm{X} \times \mathrm{Wc})\end{array}$ & $\begin{array}{c}\mathrm{KV} 10 \\
(\mathrm{X} \times \mathrm{Wc})\end{array}$ & $\begin{array}{c}\text { KV11 } \\
(\mathrm{X} \times \mathrm{Wc})\end{array}$ & & \\
\hline F1 & 105 & 3.535 & 3.411 & 3.453 & 3.399 & 3.515 & 3.326 & 3.502 & 3.350 & 3.423 & 3.472 & 3.410 & & \\
\hline F2 & 106 & 3.428 & 3.458 & 3.400 & 3.602 & 3.212 & 3.545 & 3.463 & 3.498 & 3.452 & 3.507 & 3.368 & & \\
\hline F3 & 103 & 3.494 & 3.407 & 3.406 & 3.291 & 3.628 & 3.277 & 3.461 & 3.340 & 3.448 & 3.420 & 3.445 & & \\
\hline $\mathrm{F} 4$ & 99 & 3.502 & 3.442 & 3.336 & 3.538 & 3.502 & 3.453 & 3.286 & 3.430 & 3.485 & 3.317 & 3.524 & & \\
\hline \multicolumn{2}{|c|}{ Doğrusal skorlama } & \multicolumn{13}{|c|}{ Her karar verici için (XxWcxWg) toplamları } \\
\hline Fabrikalar & $\begin{array}{l}\text { Ağırlıklandırıl- } \\
\text { mamış toplam } \\
\text { skor }\end{array}$ & $\begin{array}{c}\mathrm{KV} 1 \\
(\mathrm{XxWcxWg})\end{array}$ & $\begin{array}{c}\mathrm{KV} 2 \\
(\mathrm{XxWcxWg})\end{array}$ & $\begin{array}{c}\text { KV3 } \\
(\mathrm{XxWcxWg})\end{array}$ & $\begin{array}{c}\mathrm{KV} 4 \\
(\mathrm{X} \times \mathrm{W} \times \mathrm{Wg})\end{array}$ & $\begin{array}{c}\text { KV5 } \\
(\mathrm{XxWcxWg})\end{array}$ & $\begin{array}{c}\text { KV6 } \\
(\mathrm{X} \times \mathrm{WcxWg})\end{array}$ & $\begin{array}{c}\text { KV7 } \\
(X \times W c x W g)\end{array}$ & $\begin{array}{c}\text { KV8 } \\
(\mathrm{XxWcxWg})\end{array}$ & $\begin{array}{c}\text { KV9 } \\
(\mathrm{XxWcxWg})\end{array}$ & 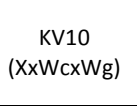 & $\begin{array}{c}\mathrm{KV} 11 \\
(\mathrm{XxWcxWg})\end{array}$ & TOPLAM & $\begin{array}{c}\text { SIRA } \\
\text { 1=En iyi }\end{array}$ \\
\hline F1 & 105 & 0.321 & 0.310 & 0.314 & 0.309 & 0.320 & 0.302 & 0.318 & 0.305 & 0.311 & 0.316 & 0.310 & 34.360 & 3 \\
\hline $\mathrm{F} 2$ & 106 & 0.312 & 0.314 & 0.309 & 0.327 & 0.292 & 0.322 & 0.315 & 0.318 & 0.314 & 0.319 & 0.306 & 34.485 & 1 \\
\hline F3 & 103 & 0.318 & 0.310 & 0.310 & 0.299 & 0.330 & 0.298 & 0.315 & 0.304 & 0.313 & 0.311 & 0.313 & 34.197 & 4 \\
\hline F4 & 99 & 0.318 & 0.313 & 0.303 & 0.322 & 0.318 & 0.314 & 0.299 & 0.312 & 0.317 & 0.302 & 0.320 & 34.377 & 2 \\
\hline \multicolumn{2}{|c|}{ Doğrusal olmayan skorlama } & \multicolumn{13}{|c|}{ Her karar verici için ağırlıklandırılmış kriter toplamları } \\
\hline Fabrikalar & $\begin{array}{c}\text { Ağırlıklandırı- } \\
\text { mamış toplam } \\
\text { skor } \\
\end{array}$ & $\begin{array}{c}\mathrm{KV} 1 \\
(\mathrm{X} \times \mathrm{Wc})\end{array}$ & $\begin{array}{c}\mathrm{KV} 2 \\
(\mathrm{X} \times \mathrm{Wc})\end{array}$ & $\begin{array}{c}\mathrm{KV} 3 \\
(\mathrm{X} \times \mathrm{Wc})\end{array}$ & $\begin{array}{c}\mathrm{KV} 4 \\
(\mathrm{X} \times \mathrm{Wc}) \\
\end{array}$ & $\begin{array}{c}\mathrm{KV} 5 \\
(\mathrm{X} \times \mathrm{Wc})\end{array}$ & $\begin{array}{c}\text { KV6 } \\
(\mathrm{X} \times \mathrm{Wc})\end{array}$ & $\begin{array}{c}\mathrm{KV7} \\
(\mathrm{X} \times \mathrm{Wc})\end{array}$ & $\begin{array}{c}\mathrm{KV8} \\
(\mathrm{X} \times \mathrm{Wc})\end{array}$ & $\begin{array}{c}\text { KV9 } \\
(X \times W c)\end{array}$ & $\begin{array}{c}\mathrm{KV} 10 \\
(\mathrm{X} \times \mathrm{Wc})\end{array}$ & $\begin{array}{c}\mathrm{KV} 11 \\
(\mathrm{X} \times \mathrm{Wc})\end{array}$ & & \\
\hline F1 & 187 & 6.340 & 6.027 & 6.135 & 5.928 & 6.331 & 5.748 & 6.251 & 5.879 & 6.039 & 6.178 & 6.044 & & \\
\hline $\mathrm{F} 2$ & 193 & 6.181 & 6.282 & 6.138 & 6.577 & 5.574 & 6.488 & 6.282 & 6.377 & 6.241 & Haz.38 & 6.114 & & \\
\hline F3 & 184 & 6.283 & 6.054 & 6.052 & 5.741 & 6.622 & 5.702 & 6.214 & 5.887 & 6.155 & 6.107 & 6.176 & & \\
\hline F4 & 177 & 6.382 & 6.293 & 6.005 & 6.May & 6.425 & 6.358 & 5.881 & 6.295 & 6.382 & 5.967 & 6.457 & & \\
\hline \multicolumn{2}{|c|}{ Doğrusal olmayan skorlama } & \multicolumn{13}{|c|}{ Her karar verici için $(\mathrm{XxWcxWg})$ toplamları } \\
\hline Fabrikalar & $\begin{array}{c}\text { Ağırlıklandırıl- } \\
\text { mamış toplam } \\
\text { skor }\end{array}$ & $\begin{array}{c}\mathrm{KV} 1 \\
(\mathrm{XxWcxWg})\end{array}$ & $\begin{array}{c}\mathrm{KV} 2 \\
(\mathrm{XxWcxWg})\end{array}$ & $\begin{array}{c}\mathrm{KV} 3 \\
(\mathrm{XxWcxWg})\end{array}$ & $\begin{array}{c}\text { KV4 } \\
\text { (XxWcxWg) }\end{array}$ & $\begin{array}{c}\text { KV5 } \\
(\mathrm{XxWcxWg})\end{array}$ & $\begin{array}{c}\text { KV6 } \\
(\mathrm{XxWcxWg})\end{array}$ & $\begin{array}{c}\text { KV7 } \\
(x \times W c x W g)\end{array}$ & $\begin{array}{c}\text { KV8 } \\
(\mathrm{XxWcxWg})\end{array}$ & $\begin{array}{c}\text { KV9 } \\
(\mathrm{XxWcxWg})\end{array}$ & $\begin{array}{c}\text { KV10 } \\
(x \times W c x W g)\end{array}$ & $\begin{array}{c}\mathrm{KV} 11 \\
(\mathrm{XxW} \times \mathrm{WWg})\end{array}$ & TOPLAM & $\begin{array}{c}\text { SIRA } \\
\text { 1=En iyi }\end{array}$ \\
\hline F1 & 187 & 0.576 & 0.548 & 0.558 & 0.539 & 0.576 & 0.523 & 0.568 & 0.534 & 0.549 & 0.562 & 0.549 & 60.818 & 4 \\
\hline F2 & 193 & 0.562 & 0.571 & 0.558 & 0.598 & 0.507 & 0.590 & 0.571 & 0.580 & 0.567 & 0.580 & 0.556 & 62.395 & 2 \\
\hline F3 & 184 & 0.571 & 0.550 & 0.550 & 0.522 & 0.602 & 0.518 & 0.565 & 0.535 & 0.560 & 0.555 & 0.561 & 60.903 & 3 \\
\hline F4 & 177 & 0.580 & 0.572 & 0.546 & 0.591 & 0.584 & 0.578 & 0.535 & 0.572 & 0.580 & 0.542 & 0.587 & 62.677 & 1 \\
\hline
\end{tabular}




\subsection{Karar Vericilerin Önem Ağırlıklarına Uygulanan Duyarlılık Analizi}

Her seçim ya da sıralama metodolojisinde daha fazla bilgi sağlamak için temel durum girdilerinin varsayımlarından birkaçına göre duyarlılık analizi gerçekleştirmek, durumun daha kapsamlı bir şekilde görülmesine yardımcı olmaktadır. Bu gibi yöntemleri uygularken, seçimi veya sıralamayı yönlendiren faktörler için maksimum faydayı sağlayan bütün duyarlılıklar değerlendirmelidir.

Bu çalışmada, buraya kadar her bir karar verici için önem ağırlıkları eşit (1/11) kabul edilmiştir. Sonrasında çalışmaya katılan ve Türk Otomotiv Ana Sanayi'nde yer alan 11 firma, sektörde her zaman eşit ağırlıkta yer alamayacağından ve objektif olmak için MATLAB'ta 11 karar verici için toplamı 1 olan, 0 ile 1 arasında 10 senaryodan oluşan sayılar türetilmiştir. Türetilen sayılar ise aşağıda Tablo 8'de verilmiştir.

Tablo 8: Türetilen Sayılar

\begin{tabular}{llllllllllll}
\hline Senaryo & \multicolumn{10}{c}{ Türetilen Sayılar } \\
\hline \hline 1. Senaryo & 0.0206 & 0.0261 & 0.0648 & 0.0974 & 0.1165 & 0.0784 & 0.1420 & 0.1263 & 0.1650 & 0.0975 & 0.0656 \\
2. Senaryo & 0.0393 & 0.1358 & 0.1679 & 0.1000 & 0.0364 & 0.0700 & 0.0484 & 0.0728 & 0.1032 & 0.1198 & 0.1065 \\
3. Senaryo & 0.1271 & 0.0805 & 0.1360 & 0.0961 & 0.1378 & 0.0444 & 0.1011 & 0.0507 & 0.1006 & 0.1036 & 0.0219 \\
4. Senaryo & 0.0522 & 0.0476 & 0.1129 & 0.1388 & 0.0653 & 0.1294 & 0.1140 & 0.0157 & 0.1032 & 0.0716 & 0.1493 \\
5. Senaryo & 0.0176 & 0.0981 & 0.0915 & 0.0979 & 0.1518 & 0.0737 & 0.1544 & 0.0997 & 0.0237 & 0.0481 & 0.1434 \\
6. Senaryo & 0.0958 & 0.0422 & 0.0737 & 0.1181 & 0.0487 & 0.1400 & 0.0573 & 0.1699 & 0.0616 & 0.1445 & 0.0482 \\
7. Senaryo & 0.0534 & 0.0263 & 0.0931 & 0.1079 & 0.0890 & 0.0724 & 0.1025 & 0.1029 & 0.1073 & 0.1013 & 0.1439 \\
8. Senaryo & 0.0488 & 0.1278 & 0.0531 & 0.0346 & 0.1117 & 0.0868 & 0.0882 & 0.1203 & 0.1374 & 0.0711 & 0.1203 \\
9. Senaryo & 0.0764 & 0.1394 & 0.1381 & 0.0528 & 0.1056 & 0.1010 & 0.0948 & 0.1436 & 0.0540 & 0.0619 & 0.0324 \\
10. Senaryo & 0.1300 & 0.0932 & 0.0725 & 0.0925 & 0.0806 & 0.0935 & 0.0805 & 0.1027 & 0.0779 & 0.1368 & 0.0399 \\
\hline
\end{tabular}

Tablo 8' de her bir karar vericiye verilen önem ağırlıkları ile fabrikaların sıralamalarındaki değişimleri belirlemek daha kolay hale gelmiştir. Önem dereceleri her metodolojide ilgili analizin son aşamasında uygulanır. Bu nedenle her bir karar vericinin sıralamalarına yol açan temel hesaplamaları kökten değiştirmeye gerek yoktur. Kullanılan 8 metot için duyarlılık analizleri yapılmıştır. Tablo 9' da belirtildiği üzere mutlak sayılar, bulanık sayılar ve sezgisel bulanık sayılardan oluşan 8 ayrı metot için Ford OTOSAN fabrikalarının duyarlıık analizlerine göre sıralamalarındaki değişimler görülmektedir. Yapılan duyarlılık analizi sonuçlarına göre Entropi Ağırlıklı Sezgisel Bulanık TOPSIS metotları (IFT-1, IFT-2, IFT-3) dışında diğer metotlar (Doğrusal Puanlama, Doğrusal Olmayan Puanlama, TOPSIS, Bulanık TOPSIS, Entropi Ağırlıklı Bulanık TOPSIS) Ford OTOSAN fabrikalarının YTZY kriterlerine göre sıralamaları değişkenlik göstermektedir. Doğrusal Puanlamaya göre duyarlılık analizi sonucunda oluşturulan senaryolarda F2 ön plana çıkmaktadır. Doğrusal Olmayan Puanlamaya ve TOPSIS göre ise F4 ön planda bulunmaktadır. Mutlak sayılara göre oluşturulmuş bu metotlara bakınca sıralamaların tutarsızlık gösterdiği görülmektedir.

Bulanık TOPSIS'e göre yapılan duyarlılık analizindeki senaryolar dağınık bir yapı göstermektedir. Ancak Entropi Ağırlıklı Bulanık TOPSIS'e göre oluşturulan senaryolarda F1 ön plana çıkmaktadır. Mutlak sayılarla oluşturulan metotlarda olduğu gibi bulanık sayılarla oluşturulan metotlardaki sıralamalarda da benzer tutarsızlıklar görülmektedir.

Entropi Ağırlıklı Sezgisel Bulanık TOPSIS (IFT-1, IFT-2, IFT-3) metotlarında ise; duyarlılık analizindeki senaryoların sıralamalarına göre tutarlılık göstermekte olup, F3 her üç metotta da ön plana çıkmaktadır. Dolayısıyla bu tutarlıı̆ı̆ın sağlanmasında, sezgisel bulanık sayıların ve 
entopi ağırlıklarının kullanımının duyarlılık analizi sonucu oluşturulan sıralamalara etki ettiği düşünülmektedir.

Tablo 9: Kullanılan Sekiz Ayrı Metot Için Yapılan Duyarlıık Analizleri Sonuçlar

\begin{tabular}{|c|c|c|c|c|c|c|c|c|c|c|c|c|}
\hline \multicolumn{13}{|c|}{ Mutlak sayılar kullanımı sonucu yapılan değerlendirmelerin duyarlııı analizi } \\
\hline & \multicolumn{4}{|c|}{ Doğrusal Puanlama } & \multicolumn{4}{|c|}{ "Doğrusal Olmayan Puanlama } & \multicolumn{4}{|c|}{ TOPSIS } \\
\hline Duyarlılık Senaryoları & F1 & $\mathrm{F} 2$ & F3 & F4 & F1 & $\mathrm{F} 2$ & F3 & F4 & F1 & $\mathrm{F} 2$ & F3 & $\mathrm{F} 4$ \\
\hline Temel Senaryo & 3 & 1 & 4 & 2 & 4 & 2 & 3 & 1 & 3 & 4 & 2 & 1 \\
\hline 1. Senaryo & 2 & 1 & 4 & 3 & 4 & 2 & 3 & 1 & 3 & 4 & 2 & 1 \\
\hline 2. Senaryo & 3 & 1 & 4 & 2 & 3 & 1 & 4 & 2 & 2 & 4 & 3 & 1 \\
\hline 3. Senaryo & 1 & 3 & 2 & 4 & 4 & 2 & 3 & 1 & 2 & 4 & 1 & 3 \\
\hline 4. Senaryo & 3 & 1 & 4 & 2 & 3 & 1 & 4 & 2 & 2 & 4 & 3 & 1 \\
\hline 5. Senaryo & 3 & 4 & 1 & 2 & 4 & 1 & 3 & 2 & 3 & 4 & 1 & 2 \\
\hline 6. Senaryo & 3 & 4 & 1 & 2 & 4 & 2 & 3 & 1 & 2 & 4 & 3 & 1 \\
\hline 7. Senaryo & 3 & 1 & 4 & 2 & 4 & 2 & 3 & 1 & 3 & 4 & 2 & 1 \\
\hline 8. Senaryo & 3 & 2 & 4 & 1 & 4 & 2 & 3 & 1 & 3 & 4 & 1 & 2 \\
\hline 9. Senaryo & 2 & 1 & 4 & 3 & 4 & 2 & 3 & 1 & 1 & 4 & 3 & 2 \\
\hline 10. Senaryo & 2 & 1 & 4 & 3 & 1 & 2 & 4 & 3 & 1 & 4 & 3 & 2 \\
\hline \multicolumn{13}{|c|}{ Bulanık sayıların kullanımı sonucu yapılan değerlendirmelerin duyarlılık analizi } \\
\hline & \multicolumn{4}{|c|}{ Bulanık TOPSIS } & \multicolumn{4}{|c|}{ Entropi Ağırlıklı Bulanık TOPSıS } & & & & \\
\hline Duyarlılık Senaryoları & F1 & $\mathrm{F} 2$ & F3 & F4 & F1 & $\mathrm{F} 2$ & F3 & F4 & & & & \\
\hline Temel Senaryo & 4 & 2 & 3 & 1 & 1 & 2 & 3 & 4 & & & & \\
\hline 1. Senaryo & 4 & 3 & 1 & 2 & 1 & 2 & 4 & 3 & & & & \\
\hline 2. Senaryo & 3 & 1 & 4 & 2 & 1 & 2 & 3 & 4 & & & & \\
\hline 3. Senaryo & 2 & 4 & 1 & 3 & 2 & 1 & 4 & 3 & & & & \\
\hline 4. Senaryo & 4 & 1 & 3 & 2 & 1 & 2 & 3 & 4 & & & & \\
\hline 5. Senaryo & 3 & 4 & 1 & 2 & 2 & 1 & 4 & 3 & & & & \\
\hline 6. Senaryo & 3 & 4 & 1 & 2 & 1 & 4 & 2 & 3 & & & & \\
\hline 7. Senaryo & 4 & 2 & 3 & 1 & 1 & 2 & 3 & 4 & & & & \\
\hline 8. Senaryo & 3 & 4 & 2 & 1 & 2 & 1 & 3 & 4 & & & & \\
\hline 9. Senaryo & 4 & 3 & 2 & 1 & 1 & 2 & 4 & 3 & & & & \\
\hline 10. Senaryo & 4 & 1 & 3 & 2 & 1 & 2 & 3 & 4 & & & & \\
\hline \multicolumn{13}{|c|}{ Sezgisel bulanık sayıların kullanımı sonucu yapılan değerlendirmelerin duyarlııık analizi } \\
\hline & \multicolumn{4}{|c|}{ IFT-1 } & \multicolumn{4}{|c|}{ IFT-2 } & \multicolumn{4}{|c|}{ IFT-3 } \\
\hline Duyarlılık Senaryoları & F1 & $\mathrm{F} 2$ & F3 & F4 & F1 & $\mathrm{F} 2$ & F3 & F4 & F1 & $\mathrm{F} 2$ & F3 & $\mathrm{F} 4$ \\
\hline Temel Senaryo & 3 & 4 & 1 & 2 & 2 & 4 & 1 & 3 & 2 & 4 & 1 & 3 \\
\hline 1. Senaryo & 3 & 4 & 1 & 2 & 2 & 4 & 1 & 3 & 2 & 4 & 1 & 3 \\
\hline 2. Senaryo & 3 & 4 & 1 & 2 & 2 & 4 & 1 & 3 & 2 & 4 & 1 & 3 \\
\hline 3. Senaryo & 3 & 4 & 1 & 2 & 2 & 4 & 1 & 3 & 2 & 4 & 1 & 3 \\
\hline 4. Senaryo & 2 & 4 & 1 & 3 & 2 & 3 & 1 & 4 & 2 & 4 & 1 & 3 \\
\hline 5. Senaryo & 3 & 4 & 1 & 2 & 2 & 3 & 1 & 4 & 2 & 4 & 1 & 3 \\
\hline 6. Senaryo & 2 & 4 & 1 & 3 & 2 & 4 & 1 & 3 & 2 & 4 & 1 & 3 \\
\hline 7. Senaryo & 3 & 4 & 1 & 2 & 2 & 3 & 1 & 4 & 2 & 4 & 1 & 3 \\
\hline 8. Senaryo & 3 & 4 & 1 & 2 & 2 & 3 & 1 & 4 & 2 & 4 & 1 & 3 \\
\hline 9. Senaryo & 3 & 4 & 1 & 2 & 2 & 4 & 1 & 3 & 2 & 4 & 1 & 3 \\
\hline 10. Senaryo & 3 & 4 & 1 & 2 & 2 & 4 & 1 & 3 & 2 & 4 & 1 & 3 \\
\hline
\end{tabular}

\section{Sonuç ve Değerlendirme}

Bu çalışmanın en önemli noktalarından bir tanesi YTZY kriterlerinin araştırmaya katılan Türk otomotiv ana sanayi firmaları tarafından ağırlıklandırılması, ağırlıklandırılan kriterler ile de Ford OTOSAN'ın fabrikalarının değerlendirmesidir. Burada ilgi çeken nokta, otomotiv ana sanayide yer alan firmalardan elde edilen genel bilgi, o firmaların içerisinde yer alan bir firmaya uygulanmış olmasıdır. Diğer bir önemli nokta ise bu çalışma ile Türk otomotiv ana sanayi, YTZY konusunda eksikliklerini görebilir ve bu eksikleri tamamlayabilir. Ayrıca bu 
çalışma sektörde yer alan firmaların önem ağırlıkları değiştikçe kararlarda gözlenen değişimleri görmek adına bir kaynaktır. Çalışmanın ilk aşamasında literatürden alınan YTZY kriterleri, Türk otomotiv ana sanayinde yer alan uzmanların görüşleri alınarak tekrardan oluşturulmuştur. İkinci aşamada YTZY kriterlerinin değerlendirilmiş, ağırlıkları yüksek olanlar kriterler yeşil geri dönüşüm ve yeşil tasarım ana kriterlerinin altında yer alan alt kriterlerde bulunduğu görülmüştür. Bunlar; yenilenebilir enerji kaynaklarının kullanılması, ömrünü tamamlamış ürünlerin geri kazanımı, tedarikçilere kendi çevre yönetim sistemini kurması için yardım edilmesi, zararlı ürünlerin ve/veya üretim prosesinin kullanımının azaltılmasını veya kullanımından kaçınılmasını sağlayan ürünlerin tasarımının yapılması, materyallerin tekrar kullanımı (reuse), geri dönüşümünü (recycle), tekrar kazanımını (recovery) sağlayan ürün tasarımının yapılması ve materyal/enerji tüketimini azaltan ürün tasarımının yapılması olarak belirlenmiştir. Bu kriterlerin arasında ağırlığı düşük olanlar yeşil depolama ana kriterinin altında bulunduğu görülmüştür. Bunlar; ürün stok seviyelerinin azaltılması, fazla stokların satılması, imalata girecek hammaddelerin/parçaların depolanması, atıl durumdaki ekipmanların değerlendirilmesi ve müşterilerle çalışılarak çevresel etkiyi azaltacak faaliyetlerde bulunulması olarak belirlenmiştir. Çalışmanın üçüncü aşamasında Ford OTOSAN'nın dört fabrikası, YTZY kriterleri kapsamında mutlak sayılar, bulanık sayılar ve sezgisel bulanık sayılar kullanılarak sekiz ayrı metotla değerlendirilmiştir. Farklı sıralamalar elde edilmiştir. Bu nedenle karar vericilerinin ağılıklarının değiştirildiği 10 farklı senaryo türetilerek sıralamalar tekrardan değerlendirilmiştir. Sonucunda Entropi Ağırlıklı Sezgisel Bulanık TOPSIS metotlarının, bu tip uygulamalarda, diğer metotlara göre daha etkin olduğu görülmüştür.

İleriki çalışmalar için öneriler:

- Bu çalışma otomotiv ana sanayi dışında farklı sanayi kollarında da gerçekleştirilebilir. Özellikle de beyaz eşya sektörüne uygulandığında çok başarılı sonuçlar elde edileceği düşünülmektedir.

- Farklı metotlar uygulanarak daha geniş çapta karşılaştırmalar yapılabilir.

- Yapılan duyarlılık analizinde belirlenen senaryolar artırılarak metotların tutarlıı̆̆ı daha derin olarak incelenebilir.

- Çalışmada yer alan YTZY kriterleri dikkate alınarak Türk Otomotiv Ana Sanayi'nde görülen eksiklikler firmalar tarafından tamamlanabilir.

- Firmaların sayısı artırılarak Türk Otomotiv Ana Sanayi daha geniş bir yelpazede incelenebilir. 


\section{Kaynaklar}

Atanassov, Krassimir T (1999), "Intuitionistic Fuzzy Sets", Intuitionistic Fuzzy Sets: Theory and Applications içinde (s.1137), Physica-Verlag, Heidelberg.

Barari, Sikhar; Agarwal, Gaurav; Zhang, W. J. Chris; Mahanty, Biswajit; Tiwari, M. Kumar (2012), "A decision framework for the analysis of green supply chain contracts: An evolutionary game approach", Expert Systems With Applications, C.39(S.3), s.2965-2976.

Borcherding, Katrin; Schmeer, Stefanie; Weber, Martin (1995), "Biases in multiattribute weight elicitation", Contributions to Decision Making, Elsevier.

Büyüközkan, Gülçin; Çifçi, Gizem (2012), "A novel hybrid MCDM approach based on fuzzy DEMATEL, fuzzy ANP and fuzzy TOPSIS to evaluate green suppliers", Expert Systems with Applications, C. 39(S.3), s.3000-3011.

Chen, Chiau-Ching; Shih, Hsu-Shih, Shyur; Huan-Jyh; Wu, Kun-Shan (2012), "A Business Strategy Selection Of Green Supply Chain Management Via An Analytic Network Process", Computers \& Mathematics with Applications, C.64(S.8), s.2544-2557.

De Luca, Aldo.; Termini, Settimo. (1972), "A Definition Of A Nonprobabilistic Entropy in The Setting Of Fuzzy Sets Theory", Information and Control, C.20(S.4), s.301-312.

Demirci, Uğraş (2014), "Green Supply Chain Management Case: Turkish Automotive Industry by Practices, Pressures And Performance", Yayınlanmamış Yüksek Lisans Tezi, University of Gavle.

Diabat, Ali; Govindan, Kannan (2011), "An Analysis of The Drivers Affecting The İmplementation Of Green Supply Chain Management", Resources, Conservation and Recycling, C.55(S.6), s.659-667.

Diabat, Ali; Khodaverdi, Roohollah; Olfat, Laya (2013), "An Exploration of Green Supply Chain Practices and Performances in An Automotive Industry", The International Journal of Advanced Manufacturing Technology, C.68(S.1), s.949-961.

Drohomeretski, Everton; Gouvea da Costa, Sergio; Pinheiro de Lima, Edson (2014), "Green Supply Chain Management", Journal of Manufacturing Technology Management, C.25(S.8), s.1105-1134.

Edwards, Ward (1977), "How to Use Multiattribute Utility Measurement for Social Decisionmaking", IEEE Transactions on Systems, Man, and Cybernetics, C.7(S.5), s.326-340.

Ghazanfari, Mehdi; Rouhani, Saeed; Jafari, Mostafa (2014), "A Fuzzy TOPSIS Model To Evaluate The Business Intelligence Competencies of Port Community Systems", Polish Maritime Research, C.21(S.2), s.86-96.

Hung, Chia-Chang; Chen, Liang-Hsuan (2009), "A Multiple Criteria Group Decision Making Model with Entropy Weight in an Intuitionistic Fuzzy Environment" (ss. 17-26).

Jain, V. K.; Sharma, Shivani (2012), "Green Supply Chain Management Practices in Automobile Industry: An Empirical Study", Journal of Supply Chain Management Systems, C.1(S.3), s.20.

Jamshidi, Rasoul; Ghomi, S. Fatemi; Karimi, Behrooz (2012), "Multi-objective green supply chain optimization with a new hybrid memetic algorithm using the Taguchi method", Scientia Iranica, C.19(S.6), s.1876-1886.

Krohling, Renato A.; Campanharo, Vinicius C. (2011), "Fuzzy TOPSIS For Group Decision Making: A Case Study For Accidents With Oil Spill in The Sea", Expert Systems With Applications, C.38(S.4), s.4190-4197.

Lin, Ru-Jen (2013), "Using fuzzy DEMATEL to evaluate the green supply chain management practices", Journal of Cleaner Production, C.40, s.32-39.

Luthra, Sunil; Kumar, Vinod; Kumar, Sanjay; Haleem, Abid (2011), "Barriers To İmplement Green Supply Chain Management in Automobile Industry Using Interpretive Structural Modeling Technique-An Indian Perspective", Journal of Industrial Engineering and Management, C.4(S.2), s.231-257.

Mathiyazhagan, Kaliyan; Diabat, Ali; Al-Refaie, Abbas; Xu, Lei (2015), "Application of analytical hierarchy process to evaluate pressures to implement green supply chain management", Journal of Cleaner Production, C.107, s.229236.

Mathiyazhagan, Kaliyan; Govindan, Kannan; NoorulHaq, A.; Geng, Yong (2013), "An ISM Approach For The Barrier Analysis in Implementing Green Supply Chain Management", Journal of Cleaner Production, C.47, s.283-297.

Rostamzadeh, Reza; Govindan, Kannan; Esmaeili, Ahmad; Sabaghi, Mahdi (2015), "Application of fuzzy VIKOR for evaluation of green supply chain management practices", Ecological Indicators, C.49, s.188-203.

Sanghavi, Punit; Rana, Yash; Shenoy, Shridhar; Yadav, Rohit (2015), "A Review On Green Supply Chain Management in Automobile Industry", International Journal of Current Engineering and Technology, C.5(S.6), s.3697-3702.

Sarkis, Joseph (2003), "A Strategic Decision Framework For Green Supply Chain Management", Journal of Cleaner Production, C.11(S.4), s.397-409.

Shang, Kuo-Chung; Lu, Chin-Shan; Li, Shaorui (2010), "A Taxonomy Of Green Supply Chain Management Capability Among Electronics-Related Manufacturing Firms in Taiwan", Journal of Environmental Management, C.91(S.5), s.1218-1226. 


\section{Eskişehir Osmangazi Üniversitesi IïBF Dergisi}

Shen, Lixin; Olfat, Laya; Govindan, Kannan; Khodaverdi, Roohollah; Diabat, Ali (2013), “A fuzzy multi criteria approach for evaluating green supplier's performance in green supply chain with linguistic preferences", Resources, Conservation and Recycling, C. 74, s.170-179.

Szmidt, Eulalia; Kacprzyk, Janusz (2001), "Entropy For Intuitionistic Fuzzy Sets", Fuzzy Sets And Systems, C.118(S.3), s.467-477.

Tseng, Ming-Lang; Chiu, Anthony S.F. (2013), "Evaluating firm's green supply chain management in linguistic preferences" Journal of cleaner production, C. 40, s.22-31.

Vanalle, Maria Rosangela ve Blanco Santos, Leandro (2014), "Green Supply Chain Management in Brazilian Automotive Sector", Management of Environmental Quality: An International Journal, C.25(S.5), s.523-541.

Vlachos, Ioannis K.; Sergiadis, George D. (2007), "Intuitionistic Fuzzy Information-Applications To Pattern Recognition", Pattern Recognition Letters, C.28(S.2), s.197-206.

Wang, Fan; Lai, Xiaofan; Shi, Ning (2011), "A multi-objective optimization for green supply chain network design", Decision Support Systems, 51(2), 262-269.

Wang, Tien-Chin; Lee, Hsien-Da; Chang, Michael Chao-Sheng (2007), "A Fuzzy TOPSIS Approach With Entropy Measure For Decision-Making Problem", Industrial Engineering and Engineering Management, 2007 IEEE International Conference on, 124-128.

Wood, David A. (2016), "Supplier Selection For Development Of Petroleum Industry Facilities, Applying Multi-Criteria Decision Making Techniques Including Fuzzy and Intuitionistic Fuzzy TOPSIS With Flexible Entropy Weighting", Journal of Natural Gas Science and Engineering, C.28, s.594-612.

Ye, Jun (2010), "Multicriteria Fuzzy Decision-Making Method Using Entropy Weights-Based Correlation Coefficients Of Interval-Valued Intuitionistic Fuzzy Sets", Applied Mathematical Modelling, C.34(S.12), s.3864-3870.

Yuce, Barış; Mastrocinque, Ernesto (2015), "A hybrid approach using the Bees Algorithm and Fuzzy-AHP for supplier selection", Handbook of Research on Advanced Computational Techniques for Simulation-Based Engineering, 171. 